\title{
Hacia un Modelo Estratégico de Interdicción Aérea Aplicable en Latinoamérica (2003-19)
}

\author{
Juan C. Hernández G.
}

\section{Introducción}

Los vuelos ilegales en Colombia, como método de transporte empleado por el narcotráfico, han generado problemas de seguridad aérea y seguridad pública que afectan el normal funcionamiento del país. Por ello, el gobierno de Colombia a través de la Fuerza Aérea Colombiana (FAC) desarrolló en 2003, en conjunto con los Estados Unidos el Convenio Air Bridge Denial (ABD), con el objetivo de reducir el tráfico aéreo ilícito de estupefacientes y sustancias psicotrópicas en Colombia y la región Caribe. En el marco de este acuerdo y de los procesos de interdicción aérea desarrollados por la FAC se ha logrado una reducción considerable en la cantidad de vuelos ilegales sobre el espacio aéreo nacional (que alcanzaría índices del 98\% entre los años 2004 y 2012) , gracias al concurso de varios factores (Estrategia) que le permitieron llevar a cabo esta labor. En este sentido, el objetivo del presente capítulo es hacer un recuento histórico de la experiencia de la FAC a partir de 2001, recorriendo los hitos y aspectos que marcaron la trayectoria de éxito de tan compleja lucha y, así mismo, efectuar un análisis a la luz de la "Ecuación Estratégica en la Estrategia Militar Operativa", establecida en 2012 por el TC (RA) Juan Ricardo Sánchez Hurtado en su libro titulado En la Mente de los Estrategas, publicado por la Escuela Superior de Guerra de Colombia. 
Si bien el concepto de la ecuación estratégica (Sánchez-Hurtado, 2013) fue formulado una década después de firmado el convenio Air Bridge Denial, éste brinda herramientas para analizar su notable formulación, la eficacia, los logros y riesgos de la FAC con respecto a la implementación del convenio y los objetivos y desafíos que éste implicaba. Este modelo define estratégia como:

$$
\begin{gathered}
E=F+M e+M o+R+E A+E n \\
\text { Estrategia }=\text { Fines }+ \text { Medios }+ \text { Modos }+ \text { Riesgos }+ \text { Estrategia del Adversario } \\
+ \text { Entorno }(\text { Sánchez-Hurtado, 2013) }
\end{gathered}
$$

La ecuación se desarrolla de manera amplia en el libro del TC (RA) Sánchez Hurtado en los diferentes niveles de la estrategia; sin embargo, en este documento solo se la abordará desde el nivel militar operativo que es el correspondiente a la interdicción aérea. Las variables involucradas en la ecuación son:

1. Fines (F). Como lo describe el autor, esta variable hace relación a la orientación de los esfuerzos hacia los objetivos propuestos, corresponde al "Qué" de la formulación de una estrategia.

2. Medios (Me). Son las capacidades y recursos disponibles para acometer la intención estratégica, involucra lo tangible e intangible que se puede emplear dentro del marco de la estrategia.

3. Modos (Mo). Esta variable da respuesta al "Cómo" dentro de una formulación estratégica, describe la manera procedimental en que se desarrollará el concepto estratégico.

4. Riesgos (R). Variable que involucra la evaluación de efectos positivos o negativos de la formulación estratégica, así como el nivel de éste a la hora de tomar decisiones.

5. Estrategia del adversario (EA). Involucra el conocimiento del cómo emplea los medios y recursos el enemigo con el fin de lograr sus propios fines.

6. Entorno (En). Esta corresponde al conocimiento del contexto político, económico, social tecnológico, ambiental y militar en el que se plantea la estrategia y las diferentes acciones (Sánchez-Hurtado, 2013).

De la combinación, análisis y desarrollo de las variables enunciadas, depende la correcta formulación de la estrategia y su éxito en el contexto ope- 
racional que, como se verá y analizará en el caso de interdicción aérea al narcotráfico, influye de manera contundente cuando se trata de combatir a un enemigo complejo y con capacidad. Debido a que este documento pretende ser una narración de eventos de manera más o menos cronológica, el desarrollo de las variables no será en el orden en que están en la fórmula, sino que se irán planteando y denominando de tal manera que al final se hará un análisis organizándolas en contexto, permitiendo conocer su impacto dentro de la historia de la interdicción aérea en Colombia.

En ese sentido, el capítulo está dividido en cuatro secciones. En la primera se presenta información para analizar la situación y el contexto que enfrentaba el país entre 2001-03, resaltando lo relacionado con el narcotráfico y los cultivos ilícitos en Colombia, las características del tráfico aéreo ilegal, el contexto nacional y el contexto internacional que auspiciarían el desarrollo de procesos de interdicción aérea en Colombia. En la segunda sección, se hace hincapié en la cadena de errores que condujeron al derribo de la aeronave OB-1408 con misioneros estadounidenses abordo en Perú (2001). Este incidente produjo la suspensión de las operaciones de interdicción aérea que se realizaban con apoyo del gobierno estadounidense en ese país y en Colombia, en el marco del Air Bridge Denial Program (ABDP). En la tercera parte del capítulo se explica cómo lo ocurrido en Perú contribuyó a que el gobierno de Colombia a través de la Fuerza Aérea Colombiana (FAC) mejorara los protocolos y procedimientos para diseñar, en conjunto con el gobierno de los Estados Unidos, el convenio Air Bridge Denial (ABD), cuyo objetivo era reducir el tráfico ilícito de estupefacientes y sustancias psicotrópicos en Colombia y la región Caribe. Luego, en la sección cuatro, se explicará cómo se desarrolló la primera operación de interdicción aérea y cuál es el balance de resultados del programa $\mathrm{ABD}$ en estos 17 años de implementación. Finalmente, se presentarán las conclusiones pertinentes.

\section{Situación y Contexto entre 2001 y 2003}

Cabe reconocer que, antes del año 2001 se desarrollaron diferentes actividades, planes, operaciones y, en general, esfuerzos para combatir al narcotráfico en todos los campos incluido el aéreo (ver capítulo 3). No obstante, después del año 2003, con el fortalecimiento de la cooperación internacional, la consolidación en diferentes aspectos operacionales (como el entrenamiento, el equipo, los procedimientos, la inteligencia entre otros) y la implemen- 
tación de una estrategia en interdicción aérea, se logró dar forma a toda una estructura militar aérea que permitió lograr importantes resultados.

Esta estructura militar aérea corresponde de manera general al área de Defensa Aérea y Antimisil de la Fuerza Aérea Colombiana que ya había sido creada desde 1989. La cual involucra otros componentes de esta institución como el comando y control, las armas aéreas representadas por los diferentes tipos de interceptores con que se cuentan, la logística aeronáutica y de los servicios, las comunicaciones aeronáuticas, la inteligencia aérea, la defensa de bases, entre otros. Esta estructura ha evolucionado durante los últimos 30 años, hasta convertirse en un modelo estructural y una herramienta eficaz en el control del espacio aéreo colombiano. Adicionalmente, esta se convirtió en un ejemplo a seguir por parte de los países de la región; en consecuencia, Colombia, hoy en día, es considerado como un referente y un exportador de experiencias y éxitos en el campo de la interdicción aérea al narcotráfico.

En pro de examinar el posible éxito operacional en interdicción aérea de la Fuerza Aérea Colombiana es necesario analizar las condiciones de la problemática del narcotráfico entre los años 2001 y 2003, periodo de transición en la lucha contra el tráfico aéreo ilegal para la región debido a los grandes cambios que experimentaría la FAC en esa etapa. Por ello, a continuación, a partir de información en materia de cultivos ilícitos, producción potencial de cocaína, circunstancias operacionales y modus operandi de la delincuencia, se presentará un panorama general de la situación a la que se enfrentaba Colombia en materia de narcotráfico y las circunstancias de la FAC en materia de interdicción aérea en el período 2001-03.

\section{Un Problema Complejo (Estrategia del Adversario, EA)}

El problema del tráfico aéreo ilegal tiene múltiples y complejos orígenes; por un lado, hay una necesidad de transportar materia prima, insumos, producto terminado, recursos, personal y, en general, todos los componentes que hacen parte de la producción de narcóticos. Por otro lado, entre los aspectos que moldearon el comportamiento aéreo ilegal y la correspondiente respuesta por parte de los gobiernos de los diferentes países involucrados están: I) la situación de los cultivos ilícitos, II) la producción de drogas ilícitas, III) el tipo de actores ilegales involucrados y IV) el origen de los controles que se desarrollaron durante la década de 1990 con respecto al tráfico aéreo ilegal, 
que como tal, no se fundamentaron simplemente en la problemática de narcotráfico sino también en factores de seguridad de los Estados Unidos.

Visto así, son cuatro los aspectos que se deben analizar brevemente dentro del complejo problema que existía entre 2001 y 2003, época en la que la interdicción aérea efectúa su mayor cambio. Estos aspectos son: narcotráfico y cultivos ilícitos, características del tráfico aéreo ilegal, el contexto nacional y el contexto internacional. Dichos aspectos demarcarían la historia y trayectoria de la interdicción aérea en Colombia.

\section{Narcotráfico y Cultivos Ilícitos (Estrategia del Adversario, EA)}

Cabe recordar que, durante la etapa de existencia de los carteles de las drogas de Medellín y Cali, la materia prima empleada para la elaboración de la cocaína que se transportaba hacia los mercados internacionales era traída desde Perú y Bolivia, que para comienzos de la década de 1990 eran los principales productores de hoja y base de coca. Esta materia prima era transportada en pequeños aviones que efectuaban vuelos ilícitos con destino a los diferentes laboratorios de procesamiento de drogas que los carteles tenían en zonas históricas controladas por ellos. Los cuales, tras la muerte de Pablo Escobar (1993) y la desarticulación del cartel de Cali en años posteriores, serían heredados por grupos al margen de la ley como las autodenominadas Autodefensas Unidas de Colombia (AUC) y las Fuerzas Armadas Revolucionarias de Colombia (FARC).

La década de 1990 se caracterizó por un crecimiento constante en los cultivos ilícitos de hoja de coca en Colombia, a tal punto que en 1995 este país superaría a Perú en cantidad de hectáreas sembradas en territorio nacional como se aprecia en la Tabla 2.1. 


\section{Tabla 2.1}

Número de hectáreas de cultivos ilícitos en Bolivia, Colombia y Perú, 1990-2002

\begin{tabular}{|c|c|c|c|c|c|c|c|c|c|c|c|c|c|}
\hline & 1990 & 1991 & 1992 & 1993 & 1994 & 1995 & 1996 & 1997 & 1998 & 1999 & 2000 & 2001 & 2002 \\
\hline \multicolumn{14}{|c|}{ CULTIVATION(1) OF COCA BUSH IN HECTARES } \\
\hline Bolivia ${ }^{(2)}$ & 50,300 & 47,900 & 45,300 & 47,200 & 48,100 & 48,600 & 48,100 & 45,800 & 38,000 & 21,800 & 14,600 & 19,900 & 24,400 \\
\hline Colombia ${ }^{(3)}$ & 40,100 & 37,500 & 37,100 & 39,700 & 44,700 & 50,900 & 67,200 & 79,400 & 101,800 & 160,100 & 163,300 & 144,800 & 102,000 \\
\hline \multirow[t]{2}{*}{ Peru ${ }^{(4)}$} & 121,300 & 120,800 & 129,100 & 108,800 & 108,600 & 115,300 & 94,400 & 68,800 & 51,000 & 38,700 & 43,400 & 46,200 & 46,700 \\
\hline & 211,700 & 206,200 & 211,500 & 195,700 & 201,400 & 214,800 & 209,700 & 194,000 & 190,800 & 220,600 & 221,300 & 210,900 & 173,100 \\
\hline \multicolumn{14}{|c|}{ POTENTIAL PRODUCTION OF DRY COCA LEAF IN METRIC TONS } \\
\hline Bolivia & 77,000 & 78,000 & 80,300 & 84,400 & 89,800 & 85,000 & 75,100 & 70,100 & 52,900 & 22,800 & 13,400 & 20,200 & 19,800 \\
\hline Colombia & 45,300 & 45,000 & 44,900 & 45,300 & 67,500 & 80,900 & 108,900 & 129,500 & 165,900 & 261,000 & 266,200 & 236,000 & 222,100 \\
\hline \multirow[t]{2}{*}{ Peru } & 196,900 & 222,700 & 223,900 & 155,500 & 165,300 & 183,600 & 174,700 & 130,600 & 95,600 & 69,200 & 46,200 & 49,300 & 52,500 \\
\hline & 319,200 & 345,700 & 349,100 & 285,200 & 322,600 & 349,500 & 358,700 & 330,200 & 314,400 & 353,000 & 325,800 & 305,500 & 294,400 \\
\hline \multicolumn{14}{|c|}{ POTENTIAL MANUFACTURE OF COCAINE IN METRIC TONS } \\
\hline Bolivia & 189 & 220 & 225 & 240 & 255 & 240 & 215 & 200 & 150 & 70 & 43 & 60 & 60 \\
\hline Colombia & 92 & 88 & 91 & 119 & 201 & 230 & 300 & 350 & 435 & 680 & 695 & 617 & 580 \\
\hline \multirow[t]{2}{*}{ Peru } & 492 & 525 & 550 & 410 & 435 & 460 & 435 & 325 & 240 & 175 & 141 & 150 & 160 \\
\hline & 774 & 833 & 866 & 769 & 891 & 930 & 950 & 875 & 825 & 925 & 879 & 827 & 800 \\
\hline
\end{tabular}

Nota: Global Illicit Drug Trends, 2003.

En el año 2000, Colombia tenía 163.300 hectáreas de hoja de coca sembradas en el territorio nacional (UNODC, 2003; FAC, 2003) y para diciembre de 2002 se estimó que eran 102.000 hectáreas, generando una producción potencial de cocaína de alrededor de 580 toneladas métricas. La Fuerza Aérea Colombiana estima que históricamente el 20\% de la producción potencial de cocaína es transportada por vía aérea y, para dicha época los registros existentes dan cuenta de casi 680 vuelos ilegales desde Colombia hacia las zonas de tránsito en Centroamérica y el Caribe. Los cultivos ilícitos en Colombia, como se aprecia en la figura 2.1, se encontraban principalmente presentes en los departamentos de Putumayo, Caquetá, Guaviare, Meta (en la parte sur), Nariño y Norte de Santander de manera intensiva, y en Vaupés, Vichada, Bolívar, Antioquia y Córdoba en menor intensidad. En consecuencia, los corredores de movilidad aéreos, terrestres y fluviales que permitían la extracción de alcaloides estaban en estas zonas o adyacentes a las mismas.

Aunado a lo anterior, estaban los problemas propios de un país con zonas históricamente abandonadas por el Estado, inseguridad, falta de presencia de autoridad de cualquier tipo, sin vías de comunicación y economías deficientes, lo que creó amplias áreas de dominio del narcotráfico, con los consecuentes impactos en cultura, medio ambiente, recrudecimiento de la violencia, entre otros.

Esta falta de presencia estatal facilitó, en gran medida, no solo el crecimiento de las estructuras delincuenciales del narcotráfico sino también el crecimiento de la infraestructura ilegal usada para la producción y eventual extracción de 
drogas. Es así como Colombia llegó a tener alrededor de 1.500 pistas ilegales a lo largo y ancho del territorio nacional. Lo cual representó una tarea ardua para la Unidad Administrativa Especial de la Aeronáutica Civil (UAEAC) y la FAC en materia de control, sin contar además los innumerables laboratorios para el procesamiento de alcaloides, las construcciones de apoyo, todo lo cual funcionaba sin ningún control ni riesgo.

\section{Figura 2.1}

Mapa de presencia de cultivos ilícitos en Colombia (2001-03)

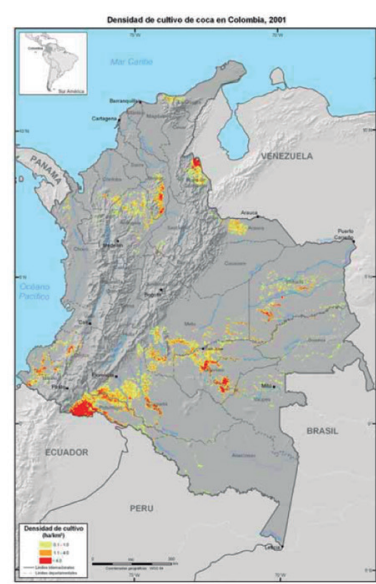

Grafica No.1

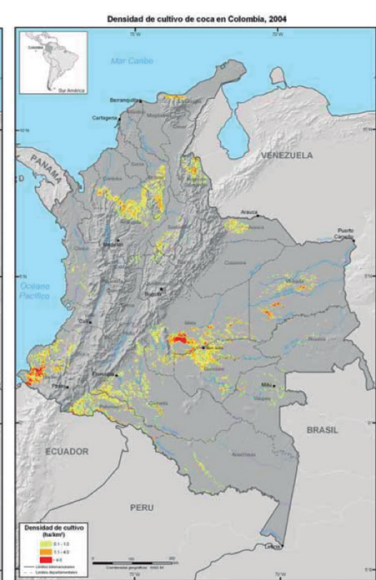

Fuente: Observatorio de Drogas de Colombia, Colombia Monitoreo de Cultivos de Coca 2004, UNODC http://www.odc.gov.co/Portals/1/publicaciones/pdf/oferta/censos/OF02012004-censo-cultivos-coca-2004-pdf

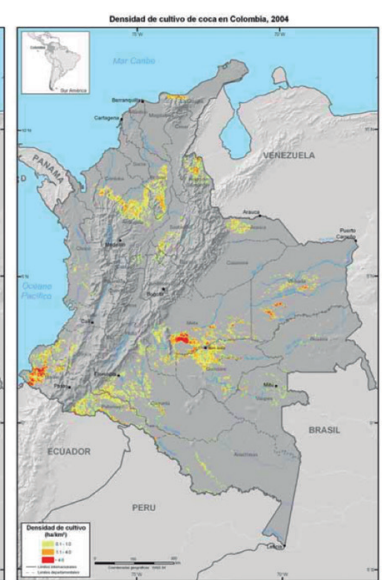

Nota: Gobierno de Colombia - Sistema de monitoreo apoyado por UNODC (como se cita en UNODC, 2005, PP. 16-17).

Características del Tráfico Aéreo Ilegal 2001-2003 (Estrategia del Adversario, EA)

Se podría llegar a pensar que cuando se habla de tráfico aéreo ilegal, se hace referencia a la trayectoria que de manera furtiva un avión no identificado realiza en alguna parte del territorio nacional $y$, parcialmente, es cierto. Sin embargo, con la experiencia acumulada durante las operaciones de interdicción aérea de las décadas de 1980 y 1990, en Defensa Aérea se llegó a la conclusión de que el comportamiento aéreo ilegal o blanco aeronáutico es un sistema de blancos que engloba componentes más allá del avión y la trayectoria que este realiza. 
Pero, este sistema de blancos sería definido hasta después de 2002. Previamente, desde 1989 a 2001 se acumularía una cantidad considerable de información producto de los diferentes seguimientos y operaciones realizados en esa época (para más información al respecto ver capítulo tres). La cual permitiría en 2002 que el Comando Aéreo de Combate No. 2 en Apiay efectuara el primer análisis formal de blanco aeronáutico enfocado en la zona oriental de Colombia, con dos grandes líneas de análisis: I) los movimientos ilegales detectados por los sensores radar y, II) los registros históricos de la aviación legal de la zona. Informe analítico que se presentó ante la Jefatura de Operaciones Aéreas de la FAC en ese mismo año, dando los primeros insumos de análisis de comportamiento aéreo ilegal que fundamentarían la futura estrategia de interdicción aérea en Colombia. Éste primer análisis de blanco aeronáutico de la zona oriental fue realizado por el personal de defensa aérea del Escuadrón 214 de Apiay. La importancia de dicha información radicó en que permitía, en primera instancia, determinar cuáles eran las zonas de operación, los horarios y los días predilectos para realizar los vuelos ilícitos. Todo esto con el propósito de efectuar los patrullajes tendientes a detectar estos vuelos y facilitar así la aplicación de los recursos aéreos correspondientes. Para ello se utilizaron todos los registros de movimientos ilegales generados por el sistema de detección de la época, en un proceso de análisis entre los años 2001 a 2003 que, en forma general, consistía en: I) la extracción de datos de los movimientos aéreos sospechosos, II) la ubicación gráfica de estos movimientos en mapas, III) el desarrollo de bases de datos, IV) el análisis de horarios, días y zonas, $\mathrm{V}$ ) el desarrollo de zonas de trabajo usando el estudio de movimientos y VI) la programación de misiones con base en el análisis obtenido.

En segunda instancia, y de manera adicional, se efectúo un análisis de todos los registros existentes en la zona oriental sobre comportamientos aéreos irregulares desarrollados por la aviación comercial de la zona, los que para esos años eran bastantes. Como componente de esta segunda parte del análisis se pudo evidenciar que muchos de los aviones con matrícula legal que operaban desde pistas legales como Villavicencio, San José del Guaviare, Calamar, Mitú, Yopal y más de una veintena de pistas no controladas en poblaciones ubicadas en zonas de producción de coca, contribuían al soporte logístico de la producción del alcaloide. Varios de los informes que se analizaron registraban la detención de aviones, pilotos, aviones, pasajeros etc., en eventos de transporte de cocaína, dinero, insumos, armamento, personal, logística y, en general, soporte para la zona de producción. 
Paralelamente al análisis efectuado en la zona oriental, se comenzaron a hacer seguimientos y levantamiento de información para la zonas norte, pacífico y central de Colombia, en pro de crear una apreciación de la situación general de comportamiento aéreo ilegal del país que permitiera conocer los corredores aéreos de movilidad internos e internacionales. Lo anterior fue esencial en el proceso de toma decisiones para todo lo relacionado con la estrategia de interdicción aérea.

Una vez recolectada y analizada toda la información a nivel nacional, se lograron extraer, entre otras, ocho grandes conclusiones que permitieron perfilar el prototipo de blanco al que se estaba enfrentando. Primera, el medio aéreo era utilizado en tres momentos diferentes: I) uso de aviones legales de matrícula colombiana para movimientos internos de logística e insumos entre pistas legales y zonas no controladas; II), las aeronaves normalmente de matrícula extranjera y en algunos casos de matrículas colombianas se utilizaban para la extracción de cocaína desde las zonas de producción hasta sus destinos internacionales, y III) los aviones con matrícula extranjera o nacional servían para el ingreso desde el extranjero de dinero o de personal.

Segunda, con el análisis de los registros operacionales más los registros de movimientos ilegales detectados se estableció para la época (2001-03) que se utilizaban mayormente aviones tipo monomotor o bimotor, cuyas velocidades oscilaban entre los 100 y 200 nudos, con matrículas nacionales o extranjeras aún legales. Tercera, con el registro de las diferentes operaciones durante la década de 1980 y 1990, se evidenció que para el abastecimiento de insumos y personal se utilizaban las pistas legales dentro del país ya fueran controladas o no controladas; para la extracción de la cocaína hacia los destinos internacionales procuraban emplear pistas ilegales acondicionadas y controladas por los mismos narcotraficantes, en aras de garantizar la seguridad en la extracción. No obstante, también se presentaron registros de extracción de alcaloides en pistas legales, controladas incluso con presencia de fuerza pública, lo cual resaltó otra vulnerabilidad en la operación y es la posibilidad de corrupción.

Cuarta, en lo referente al horario de operación de los narcotraficantes, se encontró que algunos contaban con una capacidad nocturna; pero, ellos apuntaban a llegar a sus zonas de destino en horas de la noche debido a la falta de capacidad de las fuerzas aéreas centroamericanas en materia de visión nocturna, lo cual les permitía ingresar la droga de manera segura. Quinta conclusión, para los años 2001 a 2003, los grandes volúmenes de movimientos 
aéreos ilegales estaban localizados en la zona oriental de Colombia. Cabe recordar que, entre 1999 y 2002 existió la zona de distensión que el gobierno del momento creó para adelantar un proceso de negociación de paz con las Farc. Este grupo para dicha época ya ostentaba el control total de las zonas de producción de hoja de coca y de extracción de cocaína, especialmente los Frentes 1 y 16. Por lo cual, no es una coincidencia que la mayor producción de este alcaloide se diese en la zona oriental. Existían amplias zonas con presencia de vuelos ilegales en la frontera con Venezuela en los departamentos de Arauca y Vichada, de igual manera existían amplios movimientos aéreos en los departamentos de Vaupés y Guainía, en la frontera con Brasil.

Sexta, en cuanto a las otras zonas del país se presentaban movimientos aéreos ilegales en zonas fronterizas, especialmente en La Guajira, al sur del departamento del Cesar y en la parte norte del Chocó, cerca de la frontera con Panamá. Séptima, los corredores aéreos ilegales en el norte de Colombia permanentemente empleaban rutas procedentes desde Colombia hasta Centroamérica usando las aguas internacionales en el Caribe. Era muy común la ruta La Guajira-República Dominicana, La Guajira-Honduras o Guatemala, Chocó-Guatemala o México. En la zona oriental se presentaba un alto flujo de vuelos ilegales especialmente desde Vaupés entrando y saliendo hacia Brasil, y en el sector de Arauca corredores aéreos hacia Venezuela (Cajina, 2012).

Octava conclusión, desde las décadas de 1980 y 1990, el narcotráfico con sus grandes caudales de dinero había permeado grandes sectores del país como la política y las entidades gubernamentales e incluso la fuerza pública. Debido a esto, tenían la oportunidad de monitorear todos los movimientos de las Fuerzas Militares (FFMM) y de seguridad en general, por lo que la FAC no era la excepción, lo que hacía sumamente complicado desarrollar operaciones y llevarlas a buen término.

Como se puede apreciar en los puntos anteriores, el blanco al que la FAC se enfrentaba no era sencillo. Era un adversario con capacidad, recursos, presencia a lo largo y ancho del territorio nacional y que venía operando durante los últimos 20 años sin mayores inconvenientes.

\section{Contexto Nacional (Entorno, En)}

El periodo comprendido entre 2001 y 2003 se caracteriza por ser un momento de transición, al menos, en temas de lucha contra el narcotráfico. Andrés Pastrana Arango (1998-2002) fue el presidente durante la primera parte de esta transición. Dos hitos de este gobierno son la gestión y firma 
del denominado Plan Colombia, y el intento fallido de proceso de paz con las Farc mediante la creación de la zona de distensión en el área del Caguán. En la segunda parte de la transición estuvo como presidente Álvaro Uribe Vélez, quien fue electo en este cargo por dos períodos consecutivos (2002-06 y 2006-10). Es recordado este gobierno, igualmente, por dos grandes temas; la Seguridad Democrática y su lucha frontal contra el narcotráfico, y el desmonte y desmovilización de las Auc.

El Plan Colombia o conocido también como Plan para la Paz y el Fortalecimiento del Estado nace como iniciativa del presidente Pastrana (1998) bajo la premisa de que los países desarrollados deberían apoyar a Colombia a combatir el narcotráfico, ya que esta actividad era un acelerante para el conflicto y representaba una amenaza de seguridad para las grandes potencias. Efectivamente el presidente Bill Clinton, en su momento, acoge la idea y se desarrolla todo un plan de ayuda económica que se apoya en el programa del gobierno de los EE. UU. llamado Andean Counterdrug Initiative (ACI por sus siglas en inglés) o "Iniciativa Andina Contra las Drogas". Este último, adicionalmente, recibe asistencia del Foreign Military Financing (FMF por sus siglas en inglés) o "Financiación para Fuerzas Militares Extranjeras" del Departamento de Defensa de los Estados Unidos (USDOD por sus siglas en inglés) [Veillette, 2005].

El Plan Colombia es sumamente importante en la historia reciente del país. Por un lado, entre 2001 y 2016 entregó a Colombia más de \$10,000 millones de dólares en ayuda militar (Bèle, 2016). Por otro, este emerge como la solución para fortalecer el sector policial y de defensa de Colombia, posterior a los múltiples reveses recibidos durante la década de 1990 por parte de los diferentes grupos armados ilegales que operaban en el país. Cabe anotar que los herederos de todo el emporio criminal proveniente de los extintos carteles de Medellín y Cali fueron las Farc, el autodenominado Ejército de Liberación Nacional (Eln) y los grupos de autodefensas ilegales; quienes empezaron a usar el narcotráfico como un mecanismo de financiación para ampliar su capacidad militar. Adicionalmente, hay que reconocer que el Plan Colombia también aportó en el desarrollo económico y social de algunas regiones ya que varios de sus proyectos involucraban temas de infraestructura y activación económica.

El fallido proceso de paz con las Farc es el segundo hito del gobierno de Andrés Pastrana. Este proceso tuvo sus primeros acercamientos en 1997, pero inició formalmente a partir de enero de 1999 hasta febrero de 2002. La negociación se caracterizó por sus múltiples contratiempos en temas de 
cumplimiento de lo acordado por ambas partes, lo cual causaría su eventual finalización. Durante esta etapa, las Farc crecieron exponencialmente en número y equipo adentrándose cada vez más en el empleo del narcotráfico como fuente de financiación con un afán de lograr beligerancia y reconocimiento internacional para afianzar el cumplimiento de su gran objetivo que es la toma del poder.

A través de la Resolución 85 del 14 de octubre de 1998 se creó la zona de distensión de El Caguán, la cual estaría ubicada al sur oriente de Bogotá entre los departamentos de Meta y Caquetá, con una extensión de 42.000 kilómetros cuadrados. Esta zona completamente desmilitarizada, teóricamente, garantizaría a los militantes de las Farc su seguridad mientras se desarrollaba el proceso de paz. Sin embargo, esta zona fue empleada como área de entrenamiento, zona de crecimiento y punto de lanzamiento de múltiples operaciones terroristas en contra de las poblaciones adyacentes, sin contar que adicionalmente era empleada para esconder personas secuestradas (Observatorio del programa presidencial de derechos humanos y DIH, 2003).

Durante esta primera etapa de transición, el gobierno nacional y las Farc emplearon paralelamente el tiempo del proceso de paz para fortalecerse de alguna manera. Por un lado, el Estado colombiano con la firma del Plan Colombia obtuvo recursos claves para consolidar a sus fuerzas militares. Por otro, las Farc desde la zona de distensión ampliaron sus áreas de presencia.

En la segunda etapa de transición, en junio de 2003 se lanza la política de Seguridad Democrática durante el primer mandato de Álvaro Uribe Vélez. Esta política reconoce que, en primera instancia, el terrorismo; el negocio de las drogas y las finanzas ilícitas; el tráfico de armas, municiones y explosivos, y el secuestro, la extorsión y el homicidio son amenazas que destruyen progresivamente al país y al Estado. Para enfrentarlas, se plantean cinco objetivos estratégicos: I) la consolidación del control estatal del territorio, II) la protección de la población, III) la eliminación del negocio de las drogas ilícitas en Colombia, IV) el mantenimiento de una capacidad disuasiva y V) la eficiencia, transparencia y rendición de cuentas (Política de Seguridad Democrática, 2003).

Esta política es significativa porque ayuda a hacer efectivos los recursos provenientes del Plan Colombia, en un momento en el que el Estado colombiano se encontraba en desventaja en la lucha contra el narcotráfico debido a los fallidos intentos de consolidar la paz con las Farc, y el crecimiento desmedido de este grupo y también del Eln y las Auc. Como se mencionó anteriormente, estos grupos armados ilegales incrementaron su accionar, en gran 
medida, gracias a los recursos provenientes del narcotráfico. En resumen, con la Seguridad Democrática se puede observar una intención política para combatir el terrorismo y el narcotráfico en Colombia.

El segundo evento por resaltar durante el primer gobierno de Uribe Vélez (2002-06) fue la desarticulación y desmovilización de las Autodefensas Unidas de Colombia. El proceso de desmovilización de los diferentes frentes de este grupo inició en 2003 y terminó en 2006, en actos a lo largo y ancho del país donde un total de 30,000 combatientes dejaron las armas. Esto fue significativo en el proceso de transición en interdicción aérea porque las Auc se encontraban en pleno apogeo en temas de narcotráfico, la mayoría de sus estructuras se dedicaban al trasiego y comercialización de alcaloides, así como el contrabando y otras actividades conexas. Entre esta organización que agrupaba a más de 21 grupos de autodefensas por todo el país y las Farc se dividían casi la totalidad del proceso de producción y comercialización de cocaína en Colombia.

En resumen, la situación en Colombia era compleja. Por una parte, estaban los grupos armados ilegales en todo el país, los cuales se financiaban, en gran medida, con recursos provenientes del narcotráfico y quienes, además, controlaban vastas zonas del país por falta de presencia estatal. Entretanto, la población civil estaba en medio del conflicto, víctimas de masacres y desplazamientos forzosos. El país venía de un intento fallido de proceso de paz, con un narcotráfico atomizado inicialmente, producto de la lucha y desarticulación de los carteles de Medellín y Cali, y reagrupado nuevamente por grupos al margen de la ley como las Auc y las Farc. Por otra, se firmaron acuerdos de cooperación como el Plan Colombia y se definieron cursos de acción a través de políticas como la Seguridad Democrática que brindaron herramientas al gobierno para combatir esta problemática.

\section{Contexto Internacional (Entorno, En)}

Si la situación nacional era compleja y convulsionada, igual lo era en el ámbito internacional. En esta sección, se describirá cómo lo que ocurría en el contexto internacional afectó directa o indirectamente el desarrollo de un proceso de interdicción dentro de la FAC.

Los atentados del 9 de septiembre de 2001. A las 8:46 (UTC-4 hora local de Nueva York) del nueve de septiembre de 2001 (9-11), la Torre Norte del World Trade Center (WTC por sus siglas en inglés) en Nueva York fue 
impactada por el vuelo secuestrado American Airlines 11 entre los pisos 90 y 99. Luego, a las 9:03 (UTC-4 hora local de Nueva York) fue impactada la Torre Sur por otra aeronave secuestrada, el vuelo American Airlines 175. Producto de los ataques y los fuertes incendios generados, tres edificios del WTC, incluidas las Torres Gemelas, colapsaron. En los atentados del 9-11, que incluyen también el avión secuestrado que impactó contra el Pentágono y el vuelo que se estrelló cerca de Shanksville en Pensilvania, murieron más de 3000 personas, una veintena desaparecieron y hubo más de 6000 heridos. Este ataque directo a los EE. UU. fue la puesta en práctica de uno de los planes más macabros que el terrorismo pondría en marcha en contra de este país, como bien lo explica en su informe de 450 páginas la Comisión del 9-11 (National Commission on Terrorist Attacks upon the United States, 2004).

A pesar de que este país del norte de América es una de las grandes potencias militares y económicas del planeta, nunca se esperó que el terrorismo emplease este tipo de mecanismos para hacer ataques de gran escala. El informe de la Comisión del 9-11 evidencia claramente que, si bien el sistema de defensa de los EE. UU. cuenta con todas las herramientas tecnológicas, protocolos establecidos, equipos y personal, no existía la preparación y alerta situacional suficiente para prever una posibilidad de ataque de estas proporciones.

Después del ataque, se evidenciaron grandes vacíos en temas de trabajo inter-agencial, en protocolos eficientes y enfocados a este tipo de situaciones. Lo anterior, incentivó a que las agencias gubernamentales norteamericanas actualizaran sus estructuras, protocolos y procedimientos para reaccionar ante otro eventual evento de estas características. Pero, tal vez el mayor de los cambios generados por estos ataques terroristas para los EE. UU. fue considerar a la aviación civil dentro del abanico de posibles elementos a usar para ser atacados. Esto abonó el terreno en muchos temas, especialmente, en el narcotráfico ya que generó la posibilidad de realizar interdicción aérea a aviones diferentes a los militares lo cual, a su vez, benefició el proceso de interdicción aérea en Colombia.

Narcotráfico Regional. La evolución del comportamiento del narcotráfico a nivel regional y de las rutas utilizadas está marcada fuertemente por la desaparición de los grandes carteles de las drogas en Colombia, producto de la aplicación de la ley durante la década de 1990 (UNODC, 2012). En los años ochenta, los carteles colombianos tenían la cadena completa de narcotráfico desde la producción hasta el transporte y la distribución en los 
mercados. Por esto, las rutas de movilización de alcaloides preferidas estaban ubicadas a través del Caribe, empleando diferentes islas como República Dominicana, Haití, Las Bahamas, entre otras.

A finales de la década de 1990, en Colombia el narcotráfico experimentó una nueva reorganización. Primero, ante la inminente desaparición de los carteles de Cali y Medellín, se presentaron diferentes conflictos entre las salientes organizaciones o estructuras de los carteles y los diferentes grupos armados ilegales del país como las Farc, el Eln y las Auc. Segundo, el endurecimiento de las normas y el combate al narcotráfico en Colombia causa, por un lado, la emigración de los principales cabecillas del narcotráfico hacia otros países $y$, en consecuencia, por otro lado, que los grupos armados ilegales hereden el control de toda la cadena de producción del alcaloide. Consecuentemente con la fragmentación en Colombia de los carteles de Cali y Medellín en numerosos grupos de traficantes, los ya existentes carteles mexicanos de la droga progresivamente toman el control de lo que antes hacían estos y las rutas presentan cambios ante esta evolución. Aunque la cocaína de origen colombiano es distribuida en todo el planeta, su principal mercado se encuentra en los Estados Unidos; por lo cual, los traficantes de drogas centran sus esfuerzos en acceder a dicho país. Es así como los carteles mexicanos cobran importancia asumiendo el control de las rutas de distribución de la cocaína colombiana y coordinando con los grupos ilegales en Colombia quienes se encargan de la producción, en una asociación que hasta 2020 aún está vigente.

De ahí que, las rutas aéreas y legales de distribución de narcóticos que salían de Colombia, estaban enfocadas principalmente en Centroamérica. Era muy común el destino final de los vuelos ilegales a Guatemala, Honduras, Belice, Península de Yucatán entre otros. Pero, para la misma época (2001 a 2003) existían rutas consolidadas desde la alta Guajira hasta República Dominicana, así como las rutas desde el suroriente colombiano hacia Brasil con destino a África y posteriormente a Europa.

Se puede concluir entonces que, para esta época (2001-03), el narcotráfico regional estaba en transición de pasar de ser controlado por delincuentes colombianos a delincuentes de México, en una asociación de tipo comercial en la que los colombianos producían el alcaloide para que los mexicanos efectuaran su respectiva comercialización en los mercados ilegales.

Declaración de Seguridad de las Américas en 2003. El complejo escenario entre 2001 y 2003 incluía un narcotráfico exacerbado; un comportamiento aéreo ilegal desbordado y descontrolado, una situación interna 
colombiana marcada por la violencia y el crecimiento desmedido de los grupos ilegales después de la transición desde los carteles de la droga tradicionales, y una situación regional convulsionada producto de los ataques de septiembre del 11-S en EE. UU y el crecimiento fuerte del tráfico de drogas y de los carteles mexicanos que afectaban la seguridad de Norteamérica. Se debe anotar que para 2003 en ciudad de México, la Organización de Estados Americanos (OEA) emite la declaración de seguridad de las Américas la cual en su preámbulo textualmente dice: "Reconociendo que los Estados del hemisferio enfrentamos tanto amenazas tradicionales a la seguridad como nuevas amenazas, preocupaciones y otros desafíos que por sus características complejas han determinado que la seguridad tenga un carácter multidimensional" (OEA, 2003).

Es decir, los Estados de América reconocían que las condiciones de seguridad de los países habían cambiado, que las posibles amenazas de tipo regular no constituían la única preocupación para la subsistencia de las naciones, que existían nuevas amenazas y preocupaciones que aquejan al continente, por lo que era conveniente tomar las acciones que permitiesen mitigar dichas amenazas. Este reconocimiento por parte de la OEA abre el espacio para ubicar una serie de amenazas a las cuales los Estados no les daban el nivel de importancia requerido, como lo son los delitos transnacionales, los desastres naturales, las migraciones, entre otras.

A manera de conclusión previa en este aparte de descripción del problema que se enfrentaba comenzando la década del 2000, se puede establecer que, si bien la situación de seguridad, política, delincuencia, entre otros, era sumamente compleja tanto en Colombia como en la región, también se encontraba abonado el terreno para efectuar los cambios que permitieran superar esta situación. Factores como el Plan Colombia, el enfoque en las políticas internas de seguridad nacional, la disposición política de los países de la región, la declaración del narcotráfico como una amenaza a la estabilidad de los países, fueron aprovechados para generar las campañas necesarias para combatir la delincuencia. Es a partir de este periodo de transición qué Colombia y sus FFMM lograron los mayores resultados contra el terrorismo y contra el narcotráfico. Es, precisamente, dentro de este ámbito donde se encuentra la interdicción aérea como tal con su gran éxito. 


\section{La Interdicción Aérea Antes del Derribo de una Aeronave con Misioneros Estadounidenses en Perú}

Como parte de los convenios celebrados con el gobierno de los Estados Unidos, en 2001 y años anteriores, estaban en el Comando Aéreo de Combate No. 2 en Apiay destacadas dos aeronaves tipo Cessna 550, operadas por personal norteamericano, pero controladas por controladores de armas de la FAC, específicamente del área de Defensa Aérea que volaban en su interior. Se desarrollaron innumerables misiones de vigilancia, seguimiento e interdicción de aeronaves que efectuaban vuelos ilegales a lo largo y ancho del oriente colombiano. Entre tanto, otro par de aeronaves del mismo tipo se encontraban destacadas en Iquitos, ciudad ubicada al norte de Perú y cerca de la frontera con Colombia desarrollando el mismo tipo de misiones, pero con controladores peruanos.

En ambos países se empleaban estas plataformas para la detección y seguimiento de vuelos ilegales y para los casos de interdicción se utilizaban aviones tipo A-37 en ambos países y en Colombia, adicionalmente, aeronaves tipo OV-10, AT-27 y en algunas ocasiones helicópteros artillados. Para el caso de Colombia se contaba ya por estos ańos con el sistema de comando y control que tenía más de 12 años de evolución, cuyo principio de funcionamiento era control centralizado y ejecución descentralizada de las operaciones, lo que hacía de alguna manera segura la aplicación de procedimientos de interdicción que estaba reglamentada e instrumentalizada desde el nivel central (ver capítulo tres). Pese a tener toda esta capacidad, la lucha contra el tráfico aéreo ilegal tendría un fuerte traspiés en abril de 2001 en la frontera Colomboperuana.

\section{Si Dios Eligiera... (Riesgos, R)}

Es el título del libro que la autora bautista Kristen Stagg le dio a la historia autorizada de Jim y Roni Bowers (2002), en donde se narra con gran detalle la penosa tragedia que ocurrió el 20 de abril de 2001 en la Amazonía peruana, cuando en un procedimiento de interdicción aérea por error fue derribado un avión con una familia misionera abordo, dejando dos personas fallecidas y una herida, más la destrucción de la aeronave. 
Este hecho infortunado, de singular importancia para la historia de la interdicción aérea en la región, sirvió de antecedente para mejorar los procedimientos que los países como Colombia y Perú desarrollaron para la detección, seguimiento, interceptación y final neutralización de aeronaves presuntamente dedicadas al tráfico de narcóticos. Los aprendizajes a partir de los errores cometidos durante el procedimiento contra esta aeronave en el Perú fueron la base fundamental para el desarrollo del convenio Air Bridge Denial (ABD) entre Colombia y los Estados Unidos de América de 2001 a 2003, el cual posteriormente se replicaría en varios países de la región.

El caso fue desclasificado por el gobierno estadounidense en 2010 y ha sido ampliamente analizado en las diferentes escuelas de combate y de defensa aérea tanto en Colombia como en Perú. Con la descripción de esta operación que se hace a continuación, no se pretende indicar responsabilidades o culpables, sino analizar las diferentes acciones que condujeron al siniestro. Acciones y errores que se presentaron tanto desde el punto de vista operacional por parte de los interceptores y la plataforma de interdicción, como del piloto y el avión afectado.

La familia Bowers estaba conformada por cuatro personas, Jim Bowers, su esposa Verónica, su hijo Cory (seis años) y su hija adoptiva Charity (siete meses). Este grupo de evangelizadores estadounidenses estaba en una misión en la selva amazónica de Perú. Dado el tiempo que permanecerían en ese país, la familia Bowers necesitaba una visa de residencia para Charity. Por ello, organizaron con el piloto Kevin Donaldson una misión de vuelo para llevarlos desde Iquitos (Perú) hasta Leticia (Colombia), el lugar más cercano donde había un consulado peruano para efectuar el trámite.

El 18 de abril de 2001 el piloto de la aeronave contactó vía telefónica a la torre de Iquitos e informó de su intención de efectuar un vuelo de ida y vuelta a la población de Islandia que comenzaría al día siguiente (INL, 2001). Esta población está ubicada en el borde peruano muy cerca de la denominada triple frontera entre Colombia, Perú y Brasil. El 19 de abril, la aeronave Cessna A185E (equipada con flotadores, con matrícula OB-1408 y perteneciente a la Asociación Bautista de Evangelización Mundial) despegó desde el río Amazonas con destino a la población de Islandia llevando a bordo a la familia Bowers. Posterior al despegue, el piloto se comunicó por radio con la torre de control de Iquitos para presentar su plan de vuelo, el cual fue notificado por esta entidad a su par en Leticia (INL, 2001). Una vez realizados los trámites en Leticia (Colombia) la aeronave aterrizó en Islandia (Perú) el mismo día; a continuación, se informó del arribo a la 
torre de control de Leticia y, con esto, se cerró el plan de vuelo. Después, el piloto parqueó la aeronave cerca a la población brasileña Benjamín Constant donde, según lo documenta el reporte de la investigación que se realizó posterior al siniestro, la Asociación Bautista tenía instalaciones para proteger y dar servicio a sus aeronaves, (INL, 2001).

El día del incidente, 20 de abril de 2001, a las 09:00 a.m. (hora local) despegó desde Iquitos una plataforma de interdicción aérea adscrita al convenio bilateral existente entre los Estados Unidos y Perú en temas de lucha contra el narcotráfico. La plataforma, con tripulación americana y controlador de armas peruano abordo, salió con el fin de efectuar una misión de patrulla antinarcóticos en el área de Caballococha (INL, 2001).

Paralelamente, alrededor de las 09:39 a.m., la aeronave OB-1408 despegó desde las inmediaciones de la población de Islandia rumbo hacia Iquitos siguiendo la trayectoria del río Amazonas. Sin embargo, el avión salió sin contactar a la torre de control de Leticia; por lo cual, "según las declaraciones de funcionarios de la Corporación de Aviación Civil del Perú, no se activó ningún plan de vuelo" (INL, 2001). Aunado a lo anterior, esta aeronave, por razones técnicas, sólo estaba equipada con un radio VHF y otro HF sin la posibilidad de monitorearlos al mismo tiempo. Ese día, el piloto monitoreaba únicamente las frecuencias de HF y se mantuvo así hasta que fue interceptado.

Minutos después del despegue, la aeronave fue detectada por la plataforma de interdicción la cual efectuó una identificación visual utilizando los medios técnicos de abordo, mientras se desarrollaba el proceso de identificación por parte de la Fuerza Aérea del Perú (FAP). Durante esta etapa del procedimiento, la tripulación de la plataforma decidió no acercarse a la aeronave detectada y mantener una posición lejana para no generar sospechas; por consiguiente, no fue posible obtener visualmente la matrícula de ésta. Después de 20 minutos de detectar la aeronave la FAP, utilizando los diferentes canales de comunicación y con las diferentes agencias que deberían conocer la existencia del vuelo, no había logrado la identificación de ésta, así como tampoco registró ningún tipo de comunicación por parte de la aeronave con alguna agencia de control. Por ello, el vuelo fue clasificado como "sospechoso" y, en consecuencia, se despegó un interceptor tipo A37 desde Iquitos.

Una hora después de detectar la aeronave la Fuerza Aérea del Perú aún no lograba su identificación y entre el equipo estadounidense que la reportó había dudas acerca de si ésta se ajustaba o no al perfil de un vuelo al servicio del narcotráfico (INL, 2001). Si bien, el interceptor estaba en curso hacia el 
OB-1408 y el proceso operacional se había desarrollado, parcialmente, de acuerdo con lo establecido había una gran barrera idiomática entre los agentes de la CIA y los de la FAP debido a la falta de conocimiento de inglés por parte del controlador peruano y espańol por parte de los norteamericanos, lo cual dificultó aún más la operación y causó serios problemas que desembocaron en una toma de decisiones erradas (ver capítulo uno).

A las 10:42 a.m., el OB-1408, tiene contacto visual con el A37 que lo interceptó y, de acuerdo con lo que manifestó el piloto Donaldson, intentó comunicarse con Iquitos sin lograrlo. Durante esta etapa, los movimientos de la aeronave siguiendo la trayectoria del río fueron interpretados como maniobras evasivas, lo cual reafirmó el concepto que se tenía acerca de un posible avión del narcotráfico. Por esta razón, se dio vía libre al desarrollo de las fases establecidas para la interceptación e interdicción de aeronaves en Perú las cuales se realizaron en seis minutos (para más información ver capítulo uno). A las 10:48 a.m. la aeronave interceptada es impactada por las ráfagas del A37 en el desarrollo de la última fase o neutralización. La aeronave se incendia producto de los impactos y hace un descenso brusco impactándose posteriormente en el río. En el incidente murieron Verónica Bowers y su hija Charity, mientras el piloto Donaldson sufrió una grave herida en la pierna.

\section{Figura 2.2}

Fotografía de la aeronave OB-1408 posterior al derribo

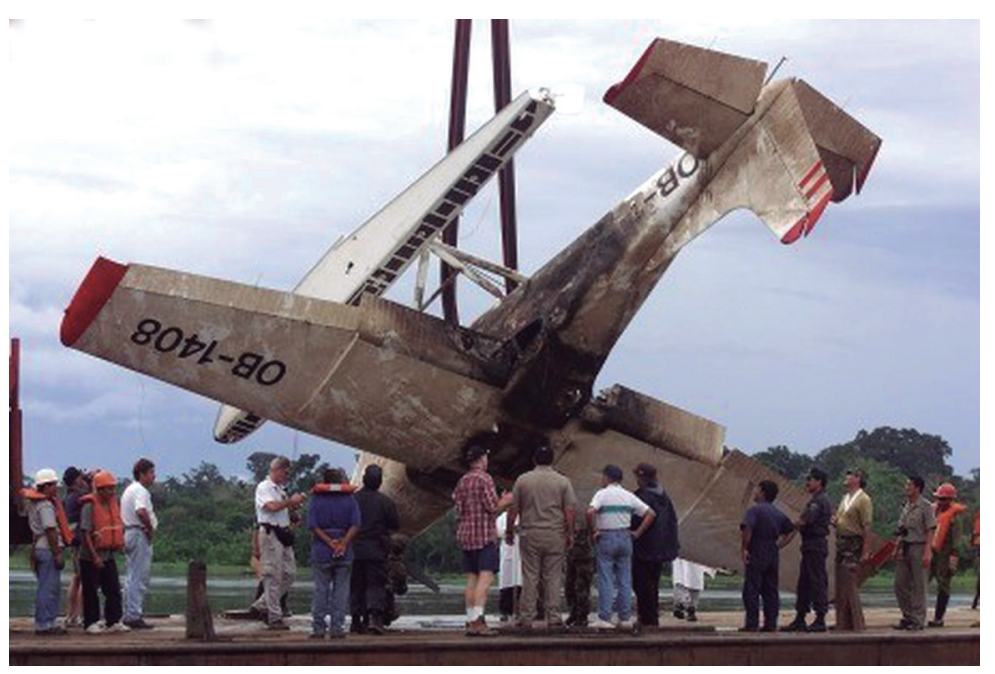

Nota: Gobierno del Perú, Ministerio de Transportes y Comunicaciones (s.f., p. 2). 


\section{Y Se Reescribe la Historia}

Este evento de interdicción fallida provocó, en ese momento, la suspensión indefinida de todas las operaciones combinadas de interdicción al narcotráfico en Perú y en todos los países involucrados en procesos similares, como Colombia (ver capítulo uno). Entre 2001 y 2003 Colombia, y muy seguramente Perú, dependían enormemente del intercambio de información con los EE. UU. para la lucha contra el narcotráfico, ya que todos los sensores, el sistema de información y demás medios técnicos que se usaban eran americanos.

Pero, al margen de lo catastrófico del evento y de los efectos negativos en la operación contra el narcotráfico, durante esos meses se generaron importantes aprendizajes en el campo operacional y procedimental. Los cuales sirvieron como insumo para perfilar un procedimiento de interdicción que, en un comienzo fue complejo, pero que eventualmente garantizó el éxito del programa. Después de analizar lo ocurrido con la familia Browers, quedaron cuatro conclusiones de porqué ocurrió este suceso. Primera, la barrera idiomática fue determinante en la comisión de errores durante el proceso. En varias oportunidades ni los controladores peruanos entendieron lo que decían los norteamericanos, ni los tripulantes norteamericanos lograron hacerse entender ni en español ni en inglés, lo cual generó una toma de decisiones erróneas.

Segunda, cada uno de los participantes dentro de la operación tenían roles definidos. Uno de los más importantes consistía en que la plataforma de interdicción era la encargada de definir sí, efectivamente, el avión interceptado era o no un avión ilegal, de tal manera que cuando el interceptor arribara ya esta etapa identificación su hubiera cumplido. En esta operación no fue así, la plataforma no determinó la legalidad del avión dejando en el interceptor la tarea de efectuar identificación visual durante el proceso de interdicción.

Tercera, a pesar de que la CIA contaba con un muy buen sistema de comunicación y comando y control para esta operación, cada participante estaba muy pendiente de sus propias coordinaciones y, por alguna razón, perdieron la alerta situacional y la perspectiva general de todo el proceso causando el desborde en la toma de decisiones.

Cuarta, la aeronave interceptada, por su parte, no cumplió con los procedimientos aeronáuticos establecidos en cuanto a la activación del plan de vuelo ni en lo referente a la comunicación en frecuencias internacionales. 
Aunado a lo anterior, el tipo de aeronave, el perfil de vuelo y la zona en la que se encontraba generaron que se clasificara como un avión sospechoso.

En resumen, el derribo del OB-1408 género una nueva doctrina y modificó los estándares operacionales involucrados en los diferentes convenios preexistentes en materia de lucha contra el narcotráfico. Estos debían ser de conocimiento y manejo por todos los participantes y, lo más importante, tenían que ser de dominio público. Bajo esta premisa, se desarrolla por lo menos para Colombia el convenio $\mathrm{ABD}$, cuyo proceso de entrenamiento comenzaría desde junio de 2002 hasta septiembre de 2003, mes en el que entraría en funcionamiento nuevamente a nivel Latinoamérica todo el sistema de la lucha contra el narcotráfico, pero, ahora con nuevas reglas.

\section{Del Air Bridge Denial Program (ABDP) al Air Bridge Denial (ABD) Segunda etapa (Medios, Me)}

El Air Bridge Denial Program (ABDP), como se conoció en su momento, fue uno de varios planes de asistencia contra el narcotráfico desarrollado por el gobierno de los EE. UU. a principios de la década de 1990 y administrado por este para aplicarse en Colombia y Perú (primera etapa) [Roncken, 1999]. Como se explicó anteriormente, este plan fue suspendido en 2001 debido a lo ocurrido con el avión OB-1408 en Perú. La investigación posterior a este hecho encontró que en operaciones de interdicción anteriores al incidente tampoco se cumplieron a cabalidad todos los procedimientos y protocolos antes de interceptar aeronaves (ver capítulo uno) [GAO, 2005]. Adicionalmente, el ABPD tuvo bastante oposición, sobre todo en el campo político y en el campo noticioso, por la preocupación de que la información de seguimientos en las operaciones proporcionada por EE. UU. fuera utilizada erróneamente en la realización de operaciones que podían causar posibles muertes de civiles, como lo que ocurrió el 20 de abril de 2001.

Los gobiernos de Estados Unidos y Perú efectuaron una investigación de muy alto nivel que involucraría por parte del primero al Departamento de Estado y de Defensa y, por parte de Perú, al Ministerio de Relaciones Exteriores y el Ministerio de Defensa con el fin de analizar las causas y efectos de la fallida operación. Las pesquisas generaron un buen número de aprendizajes que posteriormente se usaron en el desarrollo de la segunda parte del ABD.

Paralelamente, de acuerdo con lo enunciado en el reporte de 2005 de la Oficina de Responsabilidad del Gobierno de los Estados Unidos: 
El presidente colombiano, Álvaro Uribe Vélez, solicitó el reinicio del programa $\mathrm{ABD}$ para ayudar a combatir el narcotráfico. Después de las discusiones iniciales, Estados Unidos decidió ayudar a Colombia a reiniciar un programa $\mathrm{ABD}$ estableciendo que sería administrado por la Fuerza Aérea Colombiana y supervisado por la Oficina de Asuntos Internacionales de Narcóticos y Aplicación de la Ley Bureau of International Narcotics and Law Enforcement Affairs (INL por sus siglas en inglés) adscrita al Departamento de Estado. Además, los funcionarios estadounidenses dijeron que Colombia tenía una infraestructura existente que facilitaba el reinicio del programa, como bases aéreas y un centro nacional de comando aéreo (GAO, 2005, p. 5).

Esta solicitud se hizo a finales de 2001 y generó la iniciativa de rehacer un plan nuevo, completamente reforzado, con fondos provenientes del gobierno de los Estados Unidos, equipos, entrenamiento, logística y sobre todo con un detallado control político y operacional con el fin de reducir la posibilidad de errores. Este nuevo enfoque cambió la visión de la interdicción aérea al narcotráfico, de un enfoque militar a un enfoque más policial. Por lo anterior, los procedimientos que se desarrollaron se ajustaron a los conceptos de proporcionalidad y debido proceso, derechos humanos y, sobre todo, contemplaron diferentes mecanismos de verificación de la información en todos los campos antes de proceder a una operación.

Antes del reinicio del programa Air Bridge Denial en Colombia, se conformó un comité de representantes de los Departamentos de Estado, Defensa y Justicia de EE. UU., así como del gobierno colombiano, quienes desarrollaron la Carta de Acuerdo; que describe el objetivo del programa, los requisitos de seguridad, los procedimientos operativos y las responsabilidades de cada país. Esta Carta de Acuerdo, firmada en abril de 2003, estableció que el objetivo del programa era aumentar la capacidad del gobierno colombiano para detener el tráfico aéreo de drogas en Colombia. Uno de los temas más importantes que se incluyó fue el de las responsabilidades de cada una de las partes. Colombia debía suministrar el personal de tripulantes, los interceptores, crear las zonas donde el programa se aplicaría $y$, en general, el desarrollo de las operaciones diarias; para el gobierno de los EE. UU. se estableció que asignaría las aeronaves de vigilancia, se encargaría del entrenamiento del personal, los fondos para el funcionamiento y, lo más importante, la revisión anual del programa.

En cuanto a las responsabilidades colombianas, se seleccionaron las tripulaciones que operarían con los equipos que los EE. UU. iba a entregar a 
Colombia. Para estas tripulaciones era obligatorio tener un nivel de inglés superior al 80\% evaluado por el Grupo Militar de los Estados Unidos en Colombia. Los comandantes de aeronave debían ser oficiales con mucha experiencia en la parte operacional, especialmente en combate aéreo. En el caso de los operadores de equipos y Directores de Misión de defensa aérea, se requería personal con mucha experiencia en operaciones de interdicción aérea de narcotráfico. Las dos primeras tripulaciones hicieron sus cursos en la ciudad de Oklahoma durante 2002 y 2003. En cuanto a los interceptores, Colombia organizó y entrenó a todas y cada una de las tripulaciones de A-37B, OV-10, AT-27, AC-47T, KFIR y AH-60 en los procedimientos de interdicción aérea acordados en el ABD.

La creación y divulgación de las Zonas Especiales de Control Aéreo (ZECA) fue acometida antes de entrar en vigor el ABD, para lo cual, fue necesario crear publicaciones para todos los pilotos civiles de Colombia, lo que incluyó modificar el Manual de Rutas y Procedimientos ATS para Colombia, así como realizar una campaña de difusión a nivel nacional para garantizar que todos los procedimientos fueran públicos.

El nuevo $\mathrm{ABD}$ en Colombia inició con la dotación de dos aviones tipo Cessna 560 (OT-47B) y la modificación adicional de dos aviones C-26 Merlín, los primeros fueron asignados a la Base Aérea de Apiay en Villavicencio y los segundos a la Escuela Militar de Aviación en Cali. Originalmente, los C-560 conocidos como OT47B fueron implementados entre 1995 y 1997 como parte de las intenciones del gobierno americano de apoyar a algunos países de Suramérica en la lucha contra el narcotráfico. Esta intención, en su momento, se tradujo en fondos para modificar una aeronave conocida como T-47A, mejorando sus motores y ampliando en 20 pulgadas más su fuselaje con el fin de instalarle un radar APG-66 (V5) usado por los aviones de combate F-16, colocando en servicio cinco aviones de este tipo que fueron usados durante la década de 1990 en este rol de interdicción aérea.

Durante los meses previos a la firma y puesta en marcha del nuevo ABD, como se mencionó previamente, la Fuerza Aérea Colombiana tenía una serie de responsabilidades las cuales se desarrollaron en coordinación con organizaciones del gobierno de los Estados Unidos de América. Estas responsabilidades incluyeron un gran número de actividades preparatorias, entre las que estaban el entrenamiento de tripulaciones tanto de los aviones de seguimiento como de los de combate, la adecuación de instalaciones, el diseńo de protocolos operacionales, los ajustes de comando y control, la emisión de normas de nivel nacional, realizar las campañas de difusión, entre otras. 
Todas estas acciones tenían como fin abonar el ambiente para dar inicio a una de las etapas más productivas operacionalmente de la FAC en la lucha contra el narcotráfico.

En junio de 2002, cuatro Oficiales Pilotos, dentro de los cuales estaría una de las primeras pilotos operacionales de combate de la FAC, y cuatro Oficiales de Defensa Aérea conformaron lo que en su momento se denominó la Clase 1. Ellos fueron destinados en comisión por seis meses a la ciudad de Oklahoma con el fin de efectuar el curso de operación de los equipos de abordo y las aeronaves. Los operadores de defensa aérea inicialmente realizaron un curso de inteligencia en la Academia Interamericana de Fuerzas Aéreas (IAAFA, por sus siglas en inglés). Posteriormente, en Oklahoma efectuaron ya con los pilotos, quienes previamente habrían efectuado los entrenamientos de simulador y curso de tierra, la parte de operación en vuelo, entrenamiento que se extendió hasta finales de noviembre de 2002. Bajo este mismo esquema se entrenaron a dos clases más en el siguiente año. Durante este período se entrenaron tanto operadores como pilotos en Colombia en su totalidad, lo cual permitió la operación de equipos dentro del programa sin mayores inconvenientes hasta la fecha de emisión de este documento (2020).

En materia de adecuación de instalaciones, con recursos del programa y de la FAC se mejoraron y construyeron instalaciones para tener operación de los aviones de seguimiento en el Comando Aéreo de Combate No. 2 en Apiay y en la Escuela Militar de Aviación en Cali. Estas adecuaciones se realizaron para el inicio del programa y posteriormente, con la evolución de la operación y de los movimientos aéreos ilegales, en el Comando Aéreo de Combate No. 3 en Barranquilla. Aunque estas eran y continúan siendo las bases de operación de los aviones de seguimiento, el rendimiento, alcance y prestaciones de éstos permitirían su recuperación en todos los rincones de Colombia donde hubiese pista y combustible. De igual manera, ocurría en la mayoría de los países de Centroamérica, las Antillas mayores y países vecinos gracias a los diferentes planes de cooperación en materia de lucha contra los vuelos ilícitos.

No obstante, tener tripulaciones entrenadas e instalaciones adecuadas era solo una parte del proceso. En este sentido, contar con los protocolos operacionales era tal vez lo más importante, ya que uno de los principales riesgos al que se enfrentaba el $\mathrm{ABD}$ era la posibilidad de cometer errores como el que sucedió en Perú en 2001. Afortunadamente, gracias a los procedimientos operacionales desarrollados por parte de la FAC y el Departamento de Estado de los EE. UU., sumado a los múltiples controles y al entrenamiento constante, este programa no ha cometido ningún error operacional fatal desde 2003 hasta el 2020. 
Para el lanzamiento del programa oficialmente se desarrolló un procedimiento denominado "Reglamentación Interna No. 04-20-340" del comando de la FAC. Este documento establecía todas las definiciones, procedimientos, registros y controles que la interdicción aérea en Colombia debía observar en los casos operacionales contra cualquier aeronave que violara el espacio aéreo nacional y el cual estaba alineado directamente con el convenio ABD firmado con los EE. UU. el 28 de abril de 2003 en el mismo sentido. En este documento se establecieron tres fases procedimentales para la interceptación y neutralización de aeronaves. La fase 1 corresponde a la identificación visual y al establecimiento de comunicación, la etapa 2 a disparos de advertencia y la fase 3 implica la neutralización de la aeronave.

Posteriormente, en el ańo 2007 la RI-340 se actualizó y mejoró convirtiéndose en la RI-444. En abril de 2019, se realizó una tercera revisión y mejora que concluiría en el Procedimiento OA-JEC-PE-014. Estos procedimientos operacionales fueron y siguen siendo la columna vertebral de la interdicción aérea en Colombia, ya que no solo garantizaron la no comisión de errores, sino que también fueron transmitidos a los países que forman parte de los diferentes convenios en esta materia en Latinoamérica, convirtiéndose en un estándar operacional para la interceptación y neutralización de aeronaves del narcotráfico. Además, como parte de este proceso de preparación en materia de protocolos operacionales se efectuó la publicación en el Manual de Rutas ATS de Colombia de todo el protocolo desarrollado en pro de hacerlo público para todo el personal de pilotos no solo de Colombia sino del mundo. Es decir, con esto se transfería la responsabilidad de conocer cuáles son las acciones apropiadas por parte de las tripulaciones en caso de verse involucrados en un procedimiento de interdicción aérea.

Estas nuevas reglas operacionales obligaron a hacer ajustes en el Comando y Control con el fin de garantizar su estricto cumplimiento. El Comando y Control de la Fuerza Aérea Colombiana maneja el concepto de control centralizado y ejecución descentralizada. En otras palabras, las unidades aéreas desarrollan operaciones con alguna autonomía, pero controladas por el Centro de Comando y Control principal ubicado en Bogotá. Para el caso de las operaciones de interdicción aérea, se requirió hacer el ajuste a control total centralizado, debido a las características del procedimiento y los niveles de autorización requeridos para su desarrollo, además de requerirse de acuerdo al Convenio $\mathrm{ABD}$ la verificación procedimental de tres participantes dentro del protocolo desarrollado mediante listas de Chequeo: la FAC, la Fuerza Interagencial Conjunta del Sur (JIATF-S) de los EE. UU. con sede en La Florida (Zuñiga, 2011) y la plataforma 
aérea de interdicción participante, unidos los tres en la práctica mediante comunicación satelital. Estos procedimientos de comando y control se vieron reflejados para la época en diferentes normas de nivel nacional, como lo fueron las normas ATS para Colombia, que no solo incluyeron la totalidad de procedimientos operacionales, sino que también reglamentaron comportamientos para las tripulaciones especialmente en zonas o espacios aéreos no controlados. En el caso colombiano, estas zonas estaban coincidencialmente ubicadas en las mismas áreas de producción de cocaína y operación de grupos como las Farc, Auc, Eln, entre otros. El Convenio ABD, como parte de sus contenidos, en este sentido creó las Zonas Especiales de Control Aéreo (ZECA). Las cuales fueron de conocimiento público y las que básicamente eran los espacios aéreos en territorio colombiano donde se podían aplicar los procedimientos $\mathrm{ABD}$ por parte de la FAC hasta su última consecuencia, es decir aplicación de las tres fases. Estas zonas fueron tres, denominadas por su ubicación: norte, oriente y occidente demarcadas en la figura 2.3. Existía una denominada NO ZECA que comprendía las áreas terminales de Bogotá, Villavicencio y Medellín, en donde solo se podía aplicar la Fase 1 (Aerocivil, 2013).

\section{Figura 2.3}

Mapa de las zonas especiales de control aéreo en Colombia

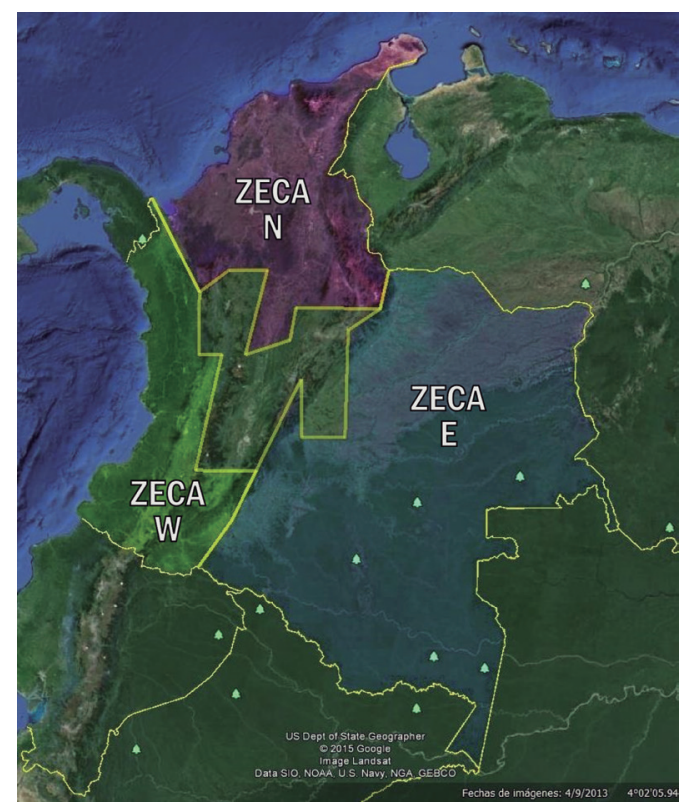

Nota: US Dept of State Geographer (C) Google 2015 
Adicionalmente, en coordinación con la Policía Nacional de Colombia, a través de la Dirección de Antinarcóticos y su oficina de Control de Aviación Civil (CACIV), inició la generación de las normas que le permitirían eventualmente la incautación de aeronaves al servicio del narcotráfico. Para ese momento contaban con un marco jurídico emanado de las diferentes resoluciones que emitía el Consejo Nacional de Estupefacientes que apuntaban al control de todo lo relacionado con narcotráfico, desde precursores hasta propiedades y capitales. Estas constituyeron la base de la Resolución 024 de la Dirección Nacional de Estupefacientes del 2006, la cual a 2020 se encuentra vigente y sometió, en su momento y en adelante, a control permanente a todas las aeronaves nacionales o extranjeras de aviación no comercial que operaran en espacio aéreo colombiano y/o la infraestructura aeroportuaria controlada o no.

Finalmente, como preparativo al lanzamiento del nuevo programa, era necesario efectuar una campaña de difusión de todos los procedimientos. Lo ocurrido con el vuelo OB-1408 en 2001 en Perú alertó acerca de la importancia de que los pilotos comerciales conocieran cuál era el protocolo y los procedimientos en caso de ser interceptado dada la inexistencia, hasta ese momento, de un proceso estándar debidamente entrenado, reglamentado, en español e inglés. Para esa época todo era de carácter secreto, sumamente reservado. Dentro de esa campaña de difusión, estuvo no solo la publicación de los procedimientos si no todo un despliegue informativo a nivel de aeropuertos, escuelas de aviación y empresas aeronáuticas.

\section{Estrategia de Interdicción Aérea (Modos, Mo)}

Cuando el tema es estrategia de interdicción aérea a narcotráfico, saltan a la vista algunos conceptos claves para entender el alcance de esta: estrategia, doctrina, narcotráfico y relaciones internacionales.

El concepto de estrategia ha sido ampliamente definido en todas las etapas de la humanidad. Por ejemplo, la Real Academia de la Lengua Española (RAE) lo define como:

estrategia. Del latín strateğa (provincia bajo el mando de un general’, y

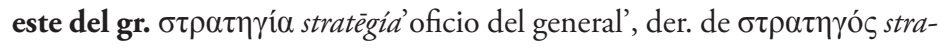
tēgós (general.

1. f. Arte de dirigir las operaciones militares. 


\section{2. f. Arte, traza para dirigir un asunto.}

3. f. Mat. En un proceso regulable, conjunto de las reglas que aseguran una decisión óptima en cada momento (RAE, 2017).

En este contexto, pero en su definición más actual y para la FAC, la estrategia es el arte y la ciencia para emplear los recursos y capacidades con el fin de alcanzar un objetivo determinado (MABDA, 2013). De tal manera que, para el caso de interdicción aérea del más alto nivel de conducción operacional y, por lo tanto, cuando se habla de estrategia, se está conceptualizando una forma de hacer las cosas en el nivel más alto del gobierno nacional. Ahora bien, aun en este nivel, la interdicción aérea forma parte de un todo estratégico para el cual, como se verá más adelante, es fundamental estar correctamente ensamblado para lograr los resultados esperados. Son muchos los conceptos dentro de la estrategia, pero para el caso que se estudia, es importante definir el de "Divide y vencerás", atribuido a Julio Cesar por la frase Divide et impera, pero que Nicolás Maquiavelo reafirmaría en su libro Del Arte de la Guerra, en el libro V, y que también Sun Tzu en su obra El Arte de la Guerra mencionaría. Fragmentar al enemigo ha sido por mucho tiempo una forma de estrategia efectiva.

La doctrina, por su parte generalmente se define como enseñanzas, prácticas, costumbres, normas y conjunto de opiniones que, por efecto del tiempo, práctica y refinación se han convertido en un modo de funcionamiento de una comunidad o grupo humano. Existen numerosas doctrinas, entre ellas la religiosa, la política, la jurídica, entre otras. Para el caso de las operaciones militares, se reconoce como doctrina militar y es abordada de diferentes maneras dependiendo su nivel y tipo de participantes. Es así como existen en cuanto a sus niveles las doctrinas básica o estratégica, operacional y táctica, y en cuanto a los participantes existen las doctrinas militar, aérea y espacial, conjunta, combinada y coordinada (MABDA, 2013). La interdicción aérea se encuentra ubicada en la doctrina operacional y en las doctrinas conjunta, combinada y coordinada, las cuales se definirán ampliamente en el trabajo.

El tercer concepto importante de conocer es el de narcotráfico. El opio, la coca y la marihuana fueron elementos naturales empleados desde hace más de 6000 ańos con diferentes fines, entre otros medicinales, recreativos y comerciales. Las anfetaminas y las drogas de diseño fueron desarrolladas hace unos 200 ańos en laboratorio para los mismos fines. Sin embargo, es para los 
siglos XIX y XX, que estas se convirtieron en un problema económico además de social, generando economías ilegales sumamente rentables y fuera del control de los Estados, cuyos efectos trascienden al siglo XXI (López-Muñoz, González, Serrano, Antequera \& Álamo, 2011).

Una de estas economías es la de la cocaína, que ha generado durante los últimos 35 años un mercado ilegal que ha estado en continuo crecimiento y que, por razones geográficas, ha centrado su producción en países como Colombia, Ecuador, Perú y Bolivia. Este mercado ilegal puede generar a nivel mundial alrededor de $\$ 320,000$ millones de dólares o más, lo que es equivalente al 1\% del PIB mundial (OEA, 2013).

La cadena de producción de este alcaloide se divide en seis etapas. De las cuales, la comunidad internacional ha centrado sus esfuerzos en las primeras cuatro: producción, elaboración, exportación y distribución, es decir en el control de la oferta o causa. Las dos últimas etapas, que son consumo y lavado de activos (control de demanda o efecto), si bien se atacan, quedan en responsabilidad de los países consumidores (Valencia, 1999).

Con esta dinámica de combate a las drogas, centrada en el control de la oferta, se ha abierto recientemente el debate de replantear esta lucha en la comunidad internacional, ya que hasta el 2016, si bien se arrojan resultados cuantiosos en la incautación de cocaína y, en general, en los procesos de interdicción, no se aprecia una reducción del fenómeno. Por el contrario, se ha experimentado, como bien lo enuncia el Reporte Anual de Drogas de las Naciones Unidas para el 2016, un incremento considerable (ONU, 2016), por lo que en la comunidad internacional se discute la posibilidad de cambiar el enfoque de combate e irse a los efectos; es decir, al control del consumo y el combate al lavado de activos.

El último concepto por considerar es el de las relaciones internacionales. El Profesor Joseph Nye, uno de los estudiosos más importantes sobre el poder, se refiere al mismo como la capacidad de influir en los demás para lograr un objetivo; pero, también distingue una nueva forma que conjuga el Poder Blando (Soft power) y el Poder Duro (Hard power) empleado por los diferentes actores dentro del sistema internacional para lograr los objetivos propuestos (2009). Esa nueva forma estratégica de poder equilibra con mayor efectividad el alcance de un Actor Internacional, se trata del Poder Inteligente o Smart Power; equilibrando las capacidades militares con las formas amables, persuasivas y seductoras de enfrentar las diferentes problemáticas (Nye, 2009). 
Esta definición de poder en el marco del Estado es importante estudiarla en función o relación directa con la política exterior del mismo. La proyección de poder permite que los Estados tengan un amplio especio de desarrollo y protección. En un mundo donde los intereses están fundamentados en conceptos geopolíticos, el poder juega un papel importante como lo dijo Nye.

Ahora bien, generar una estrategia estándar para combatir los vuelos ilícitos requiere del conocimiento y manejo de estos conceptos. Partiendo de este preámbulo, es pertinente anotar que para el 2003, la Fuerza Aérea Colombiana contaba con un sistema de comando y control robusto, con sus componentes en un desarrollo adecuado para el control del espacio aéreo nacional, con comunicaciones, inteligencia efectiva y con muy buenos equipos de detección, sistema que venía desarrollándose desde 1989, año en el que llegan los primeros equipos al país. La parte organizativa ya se había desarrollado, la FAC contaba con una Defensa Aérea e Inteligencia Aérea funcionales que a su vez ya tenían un cúmulo amplio de información sobre aeronaves, pilotos, pistas, empresas, rutas y, en general, sobre el comportamiento del blanco aeronáutico, lo cual facilitó en gran medida, la puesta en escena del programa. A esto se le sumó, en su momento, la información y capacidad de la inteligencia norteamericana proveniente de todas las agencias participantes en la lucha contra el narcotráfico de manera global como lo son la CIA, el Buró Federal de Investigaciones (FBI por sus siglas en inglés), el Servicio de Control de Inmigración y Aduanas (ICE por sus siglas en inglés) y la Administración para el Control de las Drogas (DEA por sus siglas en inglés), entre otras.

Como se enunció previamente, la estrategia en interdicción aérea en Colombia fue una construcción progresiva basada en eventos, experiencias y la información generada por éstas. Desde 1989, año de creación de la Defensa Aérea en el país, hasta el lanzamiento del programa Air Bridge Denial en 2003, se presentaron un sinnúmero de operaciones en contra de aviones al servicio del narcotráfico, que fueron generando bases de datos rudimentarias y documentales archivadas en carpetas en las bases aéreas y en la misma Dirección de Defensa Aérea en Bogotá. Esta información empezó a digitalizarse y analizarse en 2000 paralelamente en el Comando Aéreo de Combate No. 2 en Apiay y en la Subdirección de Análisis y Seguimiento de la Dirección de Defensa Aérea en Bogotá. Este proceso de digitalización y análisis duró dos años y aportó las bases de la estrategia que delinearían lo que sería el blanco objeto de ésta. 
Producto de la revisión minuciosa de cientos de informes y documentos que se encontraban en los archivos del Escuadrón de Defensa Aérea No. 214 del Comando Aéreo de Combate No. 2 en Apiay, se encontró que históricamente los infractores e involucrados en eventos de narcotráfico, contrabando, infracciones administrativas por incumplimiento de normas ATS, movimientos sospechosos y otros comportamientos ilegales en el oriente colombiano eran los mismos. En otras palabras, pilotos y aeronaves llegaban a presentar recurrentemente hasta cuatro y cinco informes diferentes por eventos de ilegalidad y continuaban operando normalmente. Debido a ello, se diseñó la primera base de datos de diez desarrolladas en otros temas, para compilar y hacer seguimiento a aeronaves y pilotos que presentaban comportamientos ilegales.

Conocer los antecedentes producto de los registros recopilados permitió delimitar el blanco; es decir, conocer exactamente qué era lo que se estaba combatiendo desde el punto de vista aeronáutico y cuál era su estructura. En un ejercicio de análisis en 2001 se establece en el Comando Aéreo de Combate No. 2 que el blanco que se combatía era más que simples aviones, se dedujo que el blanco era sistémico y que lo componían una serie de elementos interrelacionados que eran totalmente necesarios para su funcionamiento. Los componentes de, lo que en su momento se denominó, la estructura del "Blanco Aéreo" eran seis: pilotos, infraestructura, aeronaves, empresas, personal aeronáutico y organizaciones. Todos y cada uno de estos elementos reflejaban sus acciones en diferentes momentos en los documentos que se encontraron en archivo, el blanco aéreo no funcionaba si faltaba alguno de éstos. Al determinar que el blanco aéreo era un sistema, cuya estructura era conocida y que sus componentes eran necesarios para funcionar, se pudo establecer la primera intención estratégica.

Divide et Impera (divide y reinarás) la máxima de dudoso origen, atribuida por un lado a Filipo de Macedonia (382-336 AC) y posteriormente a Julio César (100-44 AC) (Zerpa, 2017), y que sería entronizada posteriormente por Nicolás Maquiavelo en su libro El Príncipe (1513) en sus numerosas aplicaciones en la maniobra política y que Napoleón Bonaparte, el Imperio Británico e incluso los Bolcheviques y otros tantos aplicarían en sus tácticas cada uno en su forma y momento; fue el principio estratégico aplicado a la primera intención estratégica. En otras palabras, el blanco aéreo, compuesto estructuralmente por seis componentes debía ser fragmentado, analizado y atacado en cada uno de estos. Estos denominados ataques por componente se denominaron Sub-estrategias y consistían en: fortalecimiento normativo, 
alianzas inter-agenciales, análisis de comportamiento, sistema de información y cooperación internacional. Estas cinco sub-estrategias fueron usadas para atacar sistemáticamente al blanco aéreo en cada uno de sus componentes mediante la aplicación de acciones que, en su momento (2002), se tradujeron en: neutralización de aeronaves, inmovilización de aeronaves, destrucción de pistas, vigilancia de corredores aéreos, entrega de blancos e intercambio de información con otros países, acciones administrativas, identificaciones visuales, bloqueo de corredores terrestres y vinculación penal a responsables.

\section{Sub-estrategias}

Como se explicó previamente, las cinco sub-estrategias utilizadas para el ataque sistemático del blanco aéreo resultan del análisis del blanco y sus componentes, pero también de la falencia en los mismos temas a la hora de actuar contra el narcotráfico especialmente en la parte aérea. Estas cinco sub-estrategias se pueden resumir de la siguiente forma:

1. Fortalecimiento Normativo. Si bien existían normas para combatir directamente al narcotráfico tanto en lo penal como en lo administrativo y procedimental, no había normas que permitieran "cortar las alas" a los delincuentes. Por ende, se inició todo un proceso de generación de normativa que permitiera afectar directamente a pilotos, aviones, infraestructura $y$, en general, a los activos empleados para transportar no solo narcóticos sino también recursos ilegales, contrabando, armamento ilegal, entre otros. Este esfuerzo se ve cristalizado en la Resolución 0024 de 2006 expedida por la Dirección Nacional de Estupefacientes, la gestión de esta resolución fue desarrollada por la Policía Nacional.

2. Alianzas Inter-agenciales. Desde el comienzo de las operaciones contra el narcotráfico en la década de 1980, el trabajo inter-agencial fue de mucha importancia; sin embargo, fue todo un proceso de madurez (Mejía \& Gaviria, 2011) lo que llegó realmente a consolidar el resultado final que hoy se conoce como operaciones conjuntas o coordinadas. El tema de roles, celos profesionales, diferencias doctrinarias y procedimentales e incluso la corrupción hicieron de esta estrategia la más difícil de acometer. En su momento, el Centro Militar de Defensa Aérea, que posteriormente se conocería como el Centro de Comando y Control de la FAC, en este tema de interdicción aérea contó con el apoyo de la Policía Nacional, no solo en la consolidación de operaciones si no que contó con un oficial destinado en comisión que tenía 
puesto dentro de este centro. Pero, eventualmente, se volvió un problema por temas de filtración de información operacional al narcotráfico, por lo que la FAC determinó removerlo. A pesar de esto, en 2002 se hace la primera coordinación con la Policía Antinarcóticos en Villavicencio, con la entonces Oficial de la Policía Nacional seccional Villavicencio, quien comandaba el Grupo de Antinarcóticos en la zona. Esta gestión permitió realizar un sinnúmero de operaciones contra el narcotráfico en la parte aérea y abrió las puertas de la FAC a otras agencias como la Aeronáutica Civil y grupos y agencias que fortalecieron el ciclo operacional contra el blanco aéreo.

3. Análisis de comportamiento. Todas las aeronaves del mundo tienen un lugar de salida, un lugar de llegada, horarios de itinerario, velocidad, altura, cantidad de motores, usan una pista tanto para despegar como para aterrizar, rutas etc., datos que debidamente catalogados y analizados son una gran herramienta para deducir el comportamiento del blanco. Esta estrategia obligó a desenterrar toda la información que estuviese en archivos a lo largo y ancho del país, la cual fue sistematizada y empleada para determinar la forma de operar del blanco aéreo en Colombia. Adicionalmente, fue esta estrategia la que realmente permitió conocer en detalle todo el entramado operacional que el narcotráfico había logrado durante años en el campo aeronáutico para el transporte de narcóticos, armas, dinero, personal y logística.

4. Sistema de Información. Como se explicó previamente, en los años previos al lanzamiento del Programa ABD, la FAC por efecto de las diferentes operaciones que por décadas había realizado, tenía un cúmulo de información operacional, casi toda en documentos e informes que reposaban en las oficinas de los Grupos de Combate, la cual inicia su transición a convertirse en digital en 2005 con el lanzamiento del Sistema Integrado de Información Operacional (SIIO) iniciativa liderada por un Coronel de la institución. La información correspondiente a Defensa Aérea inicialmente se compilaría en bases de datos tipo Access y posteriormente en 2012 entraría a formar parte del sistema de información (SIIO) de la FAC donde se encuentra actualmente. Esta sub-estrategia fue sumamente importante ya que aportaba la totalidad de la información que se usaba para las operaciones de interdicción aérea, permitía la conexión y acceso en tiempo real en todo el país a los antecedentes de aeronaves, pilotos, pistas, eventos, imágenes, entre otros. Un sistema de información robusto, accesible y seguro para garantizar el éxito del planeamiento operacional.

5. Cooperación Internacional. Partiendo de la explicación sobre la globalización que realiza Aldo Ferrer: 
La globalización no es un hecho nuevo, pero adquiere ahora dimensiones distintas y más complejas que en el pasado...es un proceso de largo plazo, que se acelera a partir de la difusión de la revolución industrial en el siglo XIX y que adquirió nuevo impulso en la segunda mitad del XX. (1999)

Se puede entrar a entender como este fenómeno impactó todos los ámbitos de la vida de los Estados, la economía, las comunicaciones, las relaciones entre los Estados y, por supuesto, la criminalidad que logra su máxima expansión durante el siglo XX y, en especial, durante la segunda mitad de este. Esta globalización del delito transnacional impactó a los Estados en sus economías y sus propias dinámicas de violencia interna, por lo que hizo importante conectar también los mecanismos de combate a esos delitos que nacían en un país y terminaban en otro, como claramente ocurre con el narcotráfico. La conexión de mecanismos de combate al delito forma parte de todo un universo de interacciones llamada cooperación internacional. Para 2001, y previo al relanzamiento del Programa ABD en el 2003, las actividades de cooperación entre la Fuerza Aérea Colombiana y diferentes países escenario de las actividades de narcotráfico en la región eran incipientes, en el entendido que no se tenían mecanismos de intercambio de información y mucho menos de operación en contra del narcotráfico más allá de las existentes con Estados Unidos.

Con la implementación del Programa ABD en 2003 y su consecuente "inundación" de información operativa, producto de las operaciones regionales contra los vuelos ilícitos, se ubicaron claramente los corredores aéreos ilegales empleados por el narcotráfico, lo que permitió iniciar la formulación de la sub-estrategia de cooperación internacional en materia de lucha contra los vuelos ilícitos. Así el tema, se puede establecer que la cooperación en materia de interdicción aérea, como lo enuncia la Coronel (RA) Magda Usme Riveros en su tesis de Maestría:

Comenzó en el 2003 con la implementación del Programa ABD en Colombia, [...] y con la firma en el año 2004 del primer plan de asistencia en temas de interdicción aérea entre Colombia y Brasil. El plan se llamó Plan Operativo Vigente - POV y su propósito principal fue combatir de manera conjunta los vuelos aéreos ilegales, que para la época se presentaban en el área que se denomina la "cabeza del perro", en la frontera Colombo-Brasileña. (2013) 
¿Por qué Brasil? Porque para 2004 y desde una década antes el narcotráfico había desarrollado operaciones ilegales casi exclusivamente en la zona sur oriental de Colombia en límites con Brasil, convirtiendo a todos los departamentos amazónicos y de la orinoquía colombiana en escenario y ruta de extracción de alcaloides hacia África, Europa y Suramérica, con un alto volumen de movimientos aéreos por año, causando así que la cooperación en esta materia iniciara con Brasil (Rodríguez, Itzhak \& Larrea, 2013).

El éxito del convenio con Brasil causó que, luego, se hicieran procesos y ejercicios similares con Perú, República Dominicana, Honduras, Guatemala, Panamá, Ecuador y México. Convenios que permitieron una lucha eficiente en contra de los vuelos ilícitos mediante el intercambio de información, estandarización de procedimientos, entrega de vuelos sospechosos en fronteras e incluso en espacios aéreos propios y desarrollo de operaciones aéreas combinadas (COA, 2020). Aunque la sub-estrategia estaba formulada, el funcionamiento de ésta dependía del éxito del programa desarrollado y del comportamiento de los vuelos ilegales. Los diferentes POV que se firmaron están vigentes a 2020, se entrenan periódicamente y se desarrollaron cronológicamente así; con Brasil (COLBRA) en 2005, con Perú (PERCOL) en 2006, con República Dominicana (CARIBE) en 2010, con Honduras (HONCOL) en 2011, con Guatemala y Honduras en (HONCOLGUA) 2011, con Panamá (PANCOL) en 2014, con Ecuador (ANDES) en 2015 y con México (MEXCOL) en 2016.

Las cinco sub-estrategias planteadas fueron todas de vital importancia en todo el proceso de interdicción aérea en Colombia. Estas tenían como fin atacar cada una de las partes del blanco en diferente forma y su implementación se planteó con otro componente de la Estrategia de Interdicción que se denominó como "proyectos", que eran actividades por tema que daban los insumos para desarrollar las "acciones operacionales" que correspondía al último componente de la Estrategia. Los "proyectos" fueron 14 cuyo detalle no se va a explicar pero que de su análisis salían importantes decisiones operacionales. Proyectos como "aeronaves sospechosas", "pistas ilegales", “corrupción”, entre otros, dieron muy buenos resultados.

\section{Acciones Operacionales}

Como se dijo, con el empleo de 14 proyectos diferentes se lograba el desarrollo de acciones que eran las que finalmente impactaban de manera directa al blanco, estas consistían en: 
1. Neutralización de aeronaves. Acción encaminada a la negación del uso del espacio aéreo nacional mediante operaciones aéreas directas. Esta acción operacional es lo que se identifica más directamente como interdicción aérea.

2. Inmovilización de aeronaves. Acción encaminada a la captura de aeronaves en los aeropuertos antes de efectuar los vuelos ilícitos, mediante la aplicación de las diferentes normas de control desarrolladas y con apoyo de la Policía Nacional, Fiscalía General de la Nación, Dirección de Impuestos y Aduanas Nacionales y la Unidad Administrativa Especial de la Aeronáutica Civil.

3. Destrucción de pistas. El tema de pistas ilegales es históricamente más complejo de acometer debido a varios factores: su ubicación en zonas lejanas de poco acceso, ubicación adicionalmente en zonas de complicado orden público y finalmente sin propietario alguno. Aun así, se recolectó información de un gran número de pistas ilegales para intervenir.

4. Vigilancia de corredores Aéreos. Con el análisis de los diferentes movimientos aéreos ilegales históricamente recopilados se pudo establecer cuáles eran las áreas y corredores aéreos de operación, esto combinado con el análisis de comportamiento permitía efectuar vigilancia permanente con medios aéreos de interdicción.

\section{Entrega de blancos e intercambio de información con otros países.} Como se manifestó previamente, con el uso de los POV se desarrollaba esta actividad operacional que complementaba el esfuerzo desarrollado en el país. La coordinación con los otros países permite el desarrollo y consolidación de las operaciones en contra del narcotráfico (Benítez, 2014).

6. Acciones administrativas. Corresponden a todas aquellas que estaban enfocadas en sancionar, restringir o prohibir la operación del blanco aéreo desde el punto de vista administrativo, lo cual permite generar información de seguimiento vital.

7. Identificaciones visuales. Acción operacional en pro de lograr la identificación de aeronaves en diferentes comportamientos, en algunas ocasiones, no reglamentarios que permitían la aplicación de las acciones administrativas.

8. Bloqueo de corredores terrestres. Acción operacional, desarrollada en coordinación y de manera conjunta con las fuerzas de superficie, tendiente a evitar la movilización de alcaloides desde las zonas de producción hasta las zonas de extracción.

9. Vinculación penal a responsables. Ésta es tal vez la acción operacional más valiosa, la vinculación penal del delincuente después de enormes 
esfuerzos operacionales, esto es lo que realmente causa efecto en el narcotraficante.

Hasta este aparte se puede decir que los Modos de la FAC estaban listos para comenzar todo un nuevo proceso operacional en contra de los vuelos ilegales, con una estrategia que tenía identificado el blanco aéreo, que lo tenía debidamente fragmentado e identificados sus componentes, y que además tenía un abanico de sub-estrategias enfocadas en la desarticulación de éste mediante acciones operacionales. Se tenía una estrategia, medios, información, entrenamiento y voluntad política, solo faltaba comenzar nuevamente.

\section{Un Nuevo Comienzo (Fines, F)}

El objetivo principal del Programa ABD era cerrar el puente aéreo entre Colombia y Centroamérica para el transporte de drogas ilegales, dinero, armas, delincuentes y logística en general del narcotráfico. Después de casi un año de preparación en lo operacional, negociaciones en lo diplomático, jurídico y procedimental, el martes 19 de agosto de 2003 se inició el programa Air Bridge Denial oficialmente. En ese momento, había temores al respecto de los resultados de este nuevo proyecto; pero, también es cierto que la FAC contaba con todas las herramientas necesarias posibles, los procedimientos estaban revisados, las tripulaciones y controladores entrenados, las normas de control fueron emitidas y eran públicas, había toda una estrategia planteada, mucha información disponible, un sistema de comando y control robusto y a la vanguardia tecnológica y existía una alta expectativa en materia de resultados.

\section{Primeros pasos}

El primer resultado positivo dentro del nuevo programa $\mathrm{ABD}$ se dio el sábado 30 de agosto de 2003 en la pista Tío Barbas, en inmediaciones de Carurú (Vaupés) en el suroriente colombiano cerca de la frontera con Brasil, con participación de una plataforma OT47B y aviones A-37B. Si bien esta operación se desarrolla de acuerdo con lo establecido en los nuevos protocolos, no queda registro de su neutralización. Diecisiete días después de lanzado el programa $\mathrm{ABD}$ se presenta la segunda operación positiva de interdicción aérea en el marco del nuevo plan. Esta ocurrió el jueves 4 de septiembre de 2003 en horas de la mańana. Una particular operación que contó con varios ingredientes que la 
hacen merecedora de ser recordada. La primera de las circunstancias corresponde al tema del cargo de Oficial Director de Misión de las aeronaves OT-47B de interdicción aérea donadas por EE. UU. y operadas por la Fuerza Aérea Colombiana dentro del convenio. La aeronave llevaba en su interior desde el comienzo una tripulación de cinco oficiales, piloto, copiloto, operador de equipos, un Air Safety Monitor (ASM) norteamericano y un Oficial Director de Misión (ODM), cada uno con una función diferente. Particularmente, el cargo de Oficial Director de Misión era nuevo en la FAC y, en general, ninguna aeronave para la época había operado bajo este concepto que se obtuvo al entrenar con tripulaciones y bajo el esquema norteamericano.

Este ODM era la persona que dirigía todas las acciones operacionales dentro de la misión y tomaba las decisiones necesarias dentro de la cadena de comando y control para garantizar el cumplimiento de la misión. Tarea que tradicionalmente cumplía en todas las aeronaves de la FAC el piloto comandante de éstas. Todo un cambio conceptual que mereció la visita del entonces Director de Entrenamiento de Vuelo de la FAC para validar si en realidad era necesario que la aeronave llevara abordo un cargo de esta índole, ya que según visión previa el piloto comandante era quien debía ostentar este rol.

La segunda circunstancia era más de aspecto operacional; durante los dos días previos a esta operación, el sistema de alerta temprana (radares) había detectado en dos días consecutivos a las seis de la mañana un movimiento aéreo en el sector de Puerto Gaitán (Meta), en el oriente colombiano, tomando rumbo hacia el nororiente siguiendo la trayectoria del río Meta hasta ingresar a territorio venezolano. El entonces Subdirector de Análisis de la Dirección de Defensa Aérea contactó al comandante del Escuadrón de Defensa Aérea de la Base de Apiay, para que se programara una misión muy temprano en la mañana para verificar este sector porque había una alta posibilidad de que se repitiera el movimiento.

Bajo estas dos circunstancias se programó una misión de vigilancia el 4 de septiembre de 2003. En este vuelo iba a bordo el Director de Entrenamiento de Vuelo, Coronel Corredor, por demás un individuo alto y corpulento que se debió ubicar en el puesto más trasero del avión donde normalmente está el baño del avión, para observar desde ese lugar los procedimientos operacionales y determinar posteriormente si el cargo de ODM era necesario o no.

La misión despegó a las seis de la mañana y a las 6:10 a.m. ya tenía un contacto en radar con las características informadas, con lo que se inició la primera operación efectiva de interdicción aérea del ABD. La operación, sin entrar en detalles, duró unas tres horas de seguimiento y contó con la 
participación de aeronaves tipo A-37B que efectuaron la neutralización, del personal de comando y control en el Centro de Comando y Control de la FAC en Bogotá, del personal de consolidación del Grupo Aéreo del Oriente en Marandúa (Vichada). La operación terminó con la neutralización de una aeronave monomotor, tipo Cessna 206, blanco, matrícula HK-1245P. Esta aeronave, sin sus dos ocupantes que la abandonaron y se dieron a la fuga en cercanías de La Primavera, fue destruida junto con el cargamento de cocaína que llevaba en su interior. Esta operación presentó, como todas las demás en adelante, un sinnúmero de situaciones: siete radios sonando en el interior del OT47-B, aviones de combate volando en formación, procedimientos complejos que seguir, y muchas personas queriendo saber qué estaba sucediendo tanto en Bogotá como en los Estados Unidos. Lo cual generó tres grandes resultados: I) una aeronave con su cargamento de cocaína destruida, II) un cargo de ODM aprobado sin ninguna duda y III) el primer paréntesis en el funcionamiento del programa $\mathrm{ABD}$, de varios en su historia, con el propósito de analizar los pormenores de la operación, extraer los aprendizajes de esta experiencia para continuar con mayor seguridad.

\section{Sí funciona}

Bajo este esquema operacional inicia el Air Bridge Denial un recorrido de 17 años, lleno de éxitos y resultados tangibles. Como se enunció previamente en la descripción del problema, los números del blanco aéreo no eran halagadores y, específicamente, la eficiencia de interdicción aérea estaba centrada -y aún lo está- en la cantidad de vuelos ilegales sobre territorio nacional. En este sentido, se puede evidenciar que un efecto de la estrategia implementada fue una reducción drástica en la cantidad de vuelos ilegales en territorio colombiano; pero, al mismo tiempo un aumento de la cantidad de vuelos en corredores aéreos ilegales en países vecinos, es decir, un efecto globo. Este fenómeno es precisamente lo que generó el desarrollo de toda la sub-estrategia de cooperación internacional en la región en materia de lucha contra los vuelos ilegales.

Los resultados del ABD se encuentran relacionados en los informes anuales de gestión que publica la Fuerza Aérea Colombiana. Estos documentos sirvieron de insumo para la elaboración de la tabla 2.2. en la cual se pueden observar los resultados tangibles del ABD en términos de la cantidad de vuelos detectada por ańo, divididos en dos tipos de movimiento: I) traza o movimiento sospechoso territorial (TST), que corresponde a los vuelos ilegales detectados y seguidos sobre espacio aéreo territorial de Colombia; es 
decir, la tierra y hasta 12 millas náuticas de mar territorial en ambas costas y II) traza o movimiento sospechoso patrimonial (TSP), correspondiente a los vuelos ilegales detectados por fuera del espacio aéreo territorial, es decir, por fuera de las fronteras terrestres y mar territorial. Esta clasificación es de suma importancia ya que muestran la importante transición que tuvo el blanco aéreo durante estos 17 años.

\section{Tabla 2.2}

Resultados del ABD.

\begin{tabular}{|c|c|c|c|c|c|c|c|c|c|c|c|c|c|c|c|c|c|c|}
\hline AÑo & 2003 & 2004 & 2005 & 2006 & 2007 & 2008 & 2009 & 2010 & 2011 & 2012 & 2013 & 2014 & 2015 & 2016 & 2017 & 2018 & 2019 & TOTAL \\
\hline Trazas Sospechosas Territoriales & 639 & 462 & 329 & 159 & 88 & 43 & 52 & 16 & 25 & 17 & 15 & 6 & 5 & \begin{tabular}{|l|}
4 \\
\end{tabular} & 7 & 1 & 9 & 1877 \\
\hline Trazas Sospechosas Patriminiales & & & & & & 76 & 102 & 145 & 187 & 138 & 93 & 53 & 66 & 68 & 128 & 224 & 256 & 1536 \\
\hline Aeronaves Neutralizadas & 0 & 12 & 7 & 7 & 7 & 9 & 15 & 15 & 32 & 28 & 43 & 25 & 21 & 10 & 16 & 7 & 21 & 275 \\
\hline Aeronaves Inmovilizadas & 24 & 29 & 12 & 9 & 13 & 45 & 77 & 78 & 60 & 84 & 113 & 166 & 156 & 77 & 153 & 188 & 58 & 1342 \\
\hline Embarcaciones Neutralizadas & 6 & & & & 10 & 23 & 11 & 12 & 6 & 3 & 10 & 22 & 34 & 16 & 15 & 16 & 21 & 205 \\
\hline Pistas Destruidas & & & 4 & & 15 & 5 & 9 & 17 & 17 & 16 & 11 & 3 & & & 1 & & 5 & 103 \\
\hline
\end{tabular}

Nota: Elaboración propia con información de los informes de gestión FAC 2003-19.

Cuando el convenio ABD inició en 2003, los sistemas detectaron 639 vuelos ilegales todos dentro del territorio nacional colombiano, esto representa casi dos vuelos ilegales por día transportando narcóticos, armas, dinero, personal y logística del narcotráfico y grupos ilegales existentes para la época (ver gráfica 2.4) [FAC, 2014a]. Todos los movimientos estaban concentrados en las zonas de producción y de mayor complejidad en materia de orden público. Si se observa la gráfica 2.5 se puede evidenciar que por efecto de las operaciones del ABD la cantidad de vuelos ilegales sobre territorio colombiano se han reducido, para 2014 hubo un 98,6\% menos vuelos ilegales comparado con 2003. Aun así, el efecto fue un aumento en los vuelos ilegales en corredores aéreos ilegales en los países vecinos, como se aprecia en la gráfica 2.5 correspondiente al año 2014. En consecuencia, se desarrolló la sub-estrategia de Cooperación Internacional, en el afán de cerrar por completo la posibilidad de que el blanco opere totalmente, este es el motivo por el cual existen los POV con los países caribeños de República Dominicana, Honduras, Guatemala, Panamá y México. En este mismo sentido sucedió con Brasil y Perú durante el comienzo del ABD, se hicieron convenios y ejercicios que permitían perseguir a los delincuentes durante toda la trayectoria. Infortunadamente, las políticas internas de cada país, así como sus gobiernos de turno no siempre respondían a la necesidad de cooperación, causando que los delincuentes migraran y operaran desde sus territorios, como sucede con Venezuela. 


\section{Figura 2.4}

Vuelos ilegales detectados en 2003

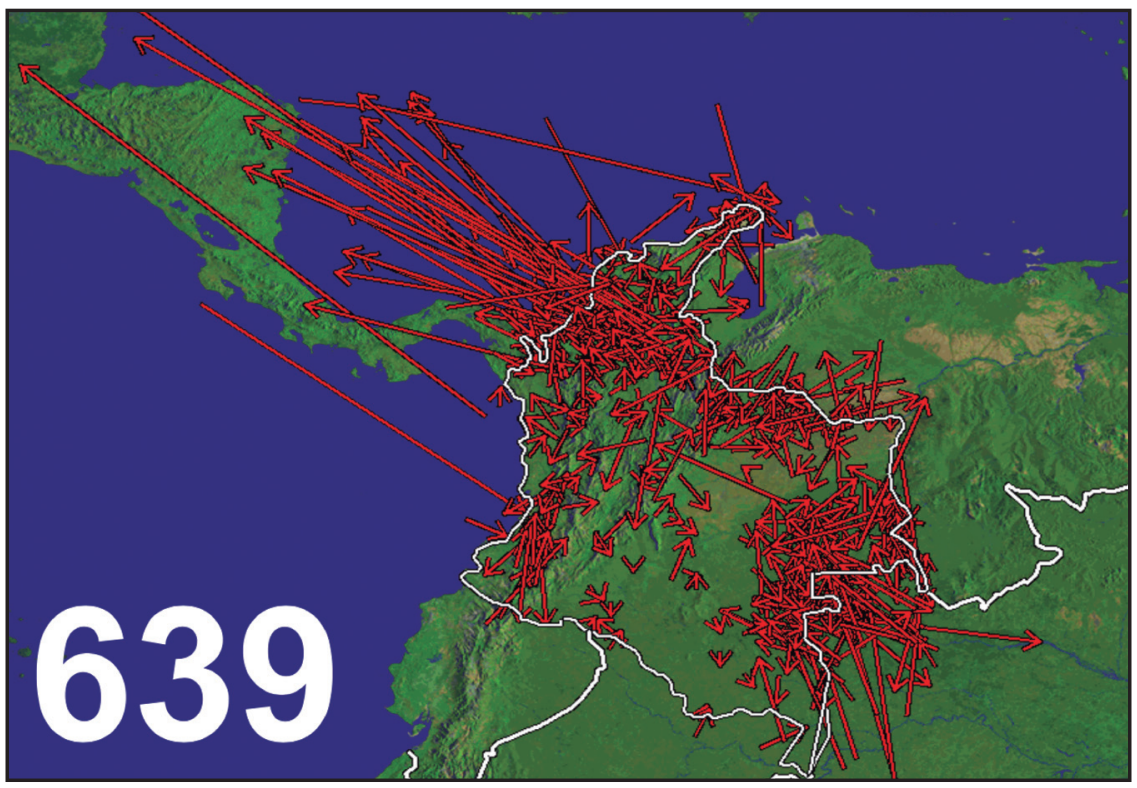

Nota: Fuerza Aérea Colombiana (2014a, p. 12).

\section{Figura 2.5}

Vuelos ilegales detectados en 2014

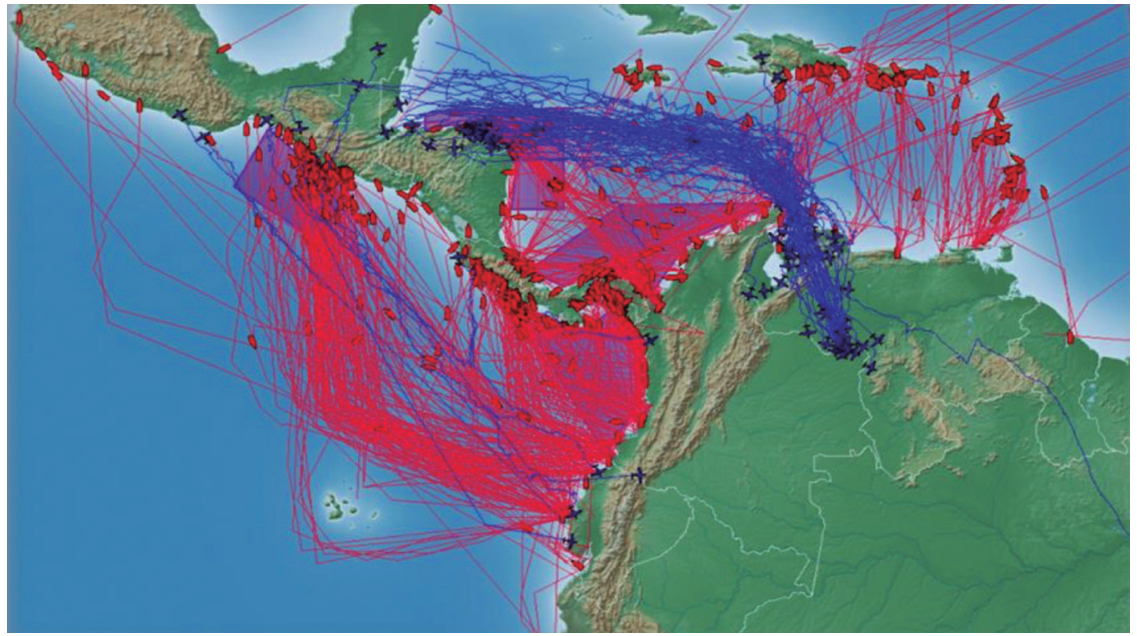

Nota: Fuerza Aérea Colombiana (2014a, p. 37). 
La segunda parte de la tabla 2.2 relaciona los resultados tangibles en materia de interdicción aérea en Colombia. Neutralizar 275 aeronaves del narcotráfico en 17 años requirió no solo una inversión económica alta sino de toda una combinación y alineación de actividades que lo hicieron posible, y si se pudiese convertir este número en kilos de cocaína no transportada se podría estar hablando de la misma cantidad de toneladas de producto. Ahora bien, neutralizar es en términos castizos sacar de circulación la aeronave mediante la acción armada, pero inmovilizar es todavía más importante, ya que cada aeronave o embarcación incautada o inmovilizada es en sí una central de datos de inteligencia. Mucha información a bordo de estas aeronaves o embarcaciones permite el seguimiento de personas, empresas, organizaciones y lugares, impactando más aun a los delincuentes ya que se ven expuestos a la acción de la ley. Colombia a través del ABD y en coordinación con las agencias del Estado en 17 años logró la inmovilización de 1342 aeronaves y 205 embarcaciones, muchas de estas con su cargamento ilegal abordo, lo cual causó gran impacto al narcotráfico. De manera similar sucedió con las 103 pistas ilegales destruidas durante el mismo periodo, cuyo impacto para la operación de los aviones ilegales fue total, sin contar con las afectaciones colaterales causadas por la vinculación penal a los dueños de los territorios que permitían la construcción y operación de estas.

El éxito del $\mathrm{ABD}$ es innegable en resultados, números y eficacia. Si se observa desde la actualidad (2020), el espacio aéreo colombiano está libre de vuelos ilegales. Razón por la cual, los delincuentes debieron considerar otros lugares o mecanismos de transporte. Pese a este éxito es innegable también que las partes restantes de la estrategia de lucha contra el narcotráfico no solo en Colombia sino en el mundo no han tenido el éxito que se esperaba. Esto debido a las fluctuantes políticas en los países en materia de control y lucha contra las drogas. En Colombia durante la etapa de lucha frontal contra el terrorismo y el narcotráfico se lograron reducciones históricas en producción de alcaloides, y por supuesto, en materia de interdicción aérea los mayores resultados. Sin embargo, con el cambio de política interna en Colombia, la falta de esfuerzos en control de oferta que se venían haciendo causó que los cultivos y la capacidad de producción potencial de cocaína se dispararan a los más altos desde la existencia del problema como se puede observar en las tablas 2.3 y 2.4 (UNODC, 2019). 


\section{Tabla 2.3}

Cultivo ilícito mundial de arbusto de coca, 2007-17 (hectáreas)

\begin{tabular}{|c|c|c|c|c|c|c|c|c|c|c|c|}
\hline & 2007 & 2008 & 2009 & 2010 & 2011 & 2012 & 2013 & 2014 & 2015 & 2016 & 2017 \\
\hline $\begin{array}{l}\text { Bolivia } \\
\text { (Estado Plurinacional de) }\end{array}$ & 28.900 & 30.500 & 30.900 & 31.000 & 27.200 & 25.300 & 23.000 & 20.400 & 20.200 & 23.100 & 24.500 \\
\hline Colombia ${ }^{a}$ & 99.000 & 81.000 & 73.000 & 62.000 & 64.000 & 48.000 & 48.000 & 69.000 & 96.000 & 146.000 & 171.000 \\
\hline Perúb & 53.700 & 56.100 & 59.900 & 61.200 & 64.400 & & & & & & \\
\hline Perúc & & & & & 62.500 & 60.400 & 49.800 & 42.900 & 40.300 & 43.900 & 49.900 \\
\hline Total & 181.600 & 167.600 & 163.800 & 154.200 & $155.600^{d}$ & 133.700 & 120.800 & 132.300 & 156.500 & 213.000 & 245.400 \\
\hline
\end{tabular}

Nota: UNODC (2019, p. 53)

\section{Tabla 2.5}

Fabricación potencial de cocaína 100\% pura, 2007-17 (toneladas)

\begin{tabular}{|c|c|c|c|c|c|c|c|c|c|c|c|}
\hline & 2007 & 2008 & 2009 & 2010 & 2011 & 2012 & 2013 & 2014 & 2015 & 2016 & 2017 \\
\hline Perú & 290 & 302 & .. &.. & .. & .. & .. & .. & .. & .. & .. \\
\hline $\begin{array}{l}\text { Total sobre la base de las } \\
\text { ratios de conversión } \\
\text { "antiguas"a }\end{array}$ & 1.077 & 886 & 920 & 862 & 815 & 738 & 662 & 746 & 936 & 1.378 & 1.743 \\
\hline $\begin{array}{l}\text { Total sobre la base de las } \\
\text { ratios de conversión } \\
\text { "nuevas"a }\end{array}$ & 1.317 & 1.143 & 1.188 & 1.134 & 1.090 & 997 & 902 & 943 & 1.124 & 1.586 & 1.976 \\
\hline
\end{tabular}

Nota: UNODC (2019, p. 54)

Ahora bien, en el marco de la implementación del proceso de interdicción aérea en Colombia, dentro de la Fuerza Aérea Colombiana se han generado unos efectos positivos, pero también se han encontrado riesgos y limitantes que se pasarán a detallar a continuación.

\section{Los Pro}

Dentro de los resultados positivos del ABD caben destacar tres aspectos. El primero se refiere a la limpieza efectiva del espacio aéreo nacional. Como se mencionó en los apartes anteriores, todas las acciones operacionales lograron el objetivo principal para Colombia, volver más seguro el espacio aéreo nacional, mediante la reducción de los vuelos ilegales en un 98,6\%. Mejorar el control del espacio aéreo fue para la FAC una de sus mejores ganancias.

El segundo aspecto está relacionado con el proceso de modernización dentro de la Fuerza Aérea. Durante lo recorrido del programa ABD la institución aérea evolucionó no solo en procedimientos operacionales, sino también en los siguientes aspectos: I) en equipos, como todo lo relacionado con aviones 
no tripulados, visión nocturna, entre otros; II) en entrenamiento, como por ejemplo la transición que se hizo para adoptar los procedimientos de la Organización del Tratado del Atlántico Norte (OTAN) y la participación en ejercicios con las Fuerzas Aéreas más poderosas del mundo, y III) en lo referente a administración, como por ejemplo, el proceso de transformación, las certificaciones en calidad, etc. Es tal vez la década de mayor evolución de la FAC en todos sus aspectos.

El último aspecto positivo se refiere al posicionamiento regional. La experiencia y éxito en interdicción aérea y, en general, en la lucha contra el terrorismo posicionó a la FAC a nivel no solo latinoamericano sino continental. La efectividad en la operación, el entrenamiento permanente, la inteligencia aérea efectiva y oportuna, y la capacidad logística hicieron que la FAC resaltara como un modelo a imitar. De ahí que se hayan logrado desarrollar nueve convenios bilaterales de interdicción aérea.

\section{Los Contra (Riesgos, R)}

Luchar contra el narcotráfico desde el punto de vista estatal trae también consigo aspectos no tan agradables que es necesario reconocer. Por un lado, está la dependencia y control. Parte de los motivos por los cuales EE. UU. acepta negociar el nuevo convenio ABD es para poder tener bajo control los resultados de las acciones en las que ellos depositaran recursos, equipos o personal. Aunque para 2020, Colombia tiene una relativa independencia en materia de defensa ${ }^{10}$, al tener equipos de fabricación norteamericana requiere tener unas relaciones amistosas con el país del norte para garantizar el flujo de repuestos, entrenamiento y actualizaciones. El convenio ABD se crea bajo la premisa de que los Estados Unidos de América es quien regula el comportamiento, flujo de información y acciones de los participantes, es quien certifica quiénes sí pueden o no participar en procesos de interdicción en el Caribe. Como ejemplo se puede tomar el caso de Venezuela, por un buen período de tiempo ha sido restringido el empleo de recursos del ABD financiados por los EE. UU. para hacer operaciones en contra del narcotráfico en las que se involucre el estado venezolano, cuestión de política.

10 El sistema radar que comenzó a finales de la década de 1980 dependía 100\% de los Estados Unidos en cuanto a funcionamiento, logística, recursos y personal. Durante la evolución del sistema, Colombia se vio forzada a desarrollar la capacidad y autonomía para sostener su operación una vez que el gobierno norteamericano, por temas políticos y presupuestales, comenzó a reducir el apoyo en este sentido. 
Por otro lado, está la cacería de brujas. El narcotráfico es una economía que genera enormes cantidades de recursos, cifras astronómicas que generan uno de los fenómenos más incómodos y peligrosos a la hora de combatirlo: la corrupción. La Fuerza Aérea Colombiana durante tres décadas completas tuvo que enfrentar, al igual que lo ha hecho todo el estado colombiano, los efectos y daños que causa la corrupción generada por el narcotráfico. Dados los resultados del convenio ABD y la efectividad de la estrategia de interdicción, se podría concluir que la lucha contra la corrupción al interior de la FAC, generada por los dineros provenientes del narcotráfico, ha sido muy efectiva. Muchos son los casos en los que el narcotráfico impactó las operaciones, muchas las ocasiones en las que se generaron innumerables mecanismos para burlar o malograr los esfuerzos para combatir a los narcos. Con dineros del narcotráfico lograron comprar a miembros de la FAC, en todas las áreas, las operaciones, el comando y control, la defensa aérea, la inteligencia, la logística y, por supuesto, los pilotos. Son varios los casos sonados y a la vez críticos que es conveniente reconocer en aras de la transparencia y también para analizar la complejidad de los riesgos y las amenazas que pueden destruir y aniquilar el mejor de los planeamientos.

Por ejemplo, Cúper Andrés Páez Doncel fue un oficial de grado teniente, especialidad piloto de la FAC, quien recibió entrenamiento en los equipos adscritos al Convenio ABD, más exactamente en los OT47B; él volaba como copiloto cuando fue descubierto como infiltrado del narcotráfico en Apiay, haciendo vuelos ilegales durante los fines de semana, dando instrucción a pilotos del narcotráfico y suministrando información operacional. En 2006 fue desvinculado de la FAC, mientras la Fiscalía realizaba la investigación penal pertinente, y en diciembre de 2007 él se accidentó y falleció en un vuelo del narcotráfico en un avión de matrícula venezolana frente a las costas de Honduras $^{11}$. Como ocurrió en dicha ocasión, la Fuerza Aérea Colombiana procesó y depuró varios casos más, permitiendo así el éxito operacional del convenio.

El narcotráfico también intento malograr operaciones en su contra, afectando las aeronaves que hacían los procesos de interdicción aérea. Por ejemplo, los A-37B, que eran empleados de manera preferencial para estos procesos, fueron afectados o saboteados en varias oportunidades durante eventos operacionales para evitar que despegaran.

$11 \mathrm{Al}$ respecto de la muerte de Cúper Andrés Páez se puede consultar la nota de prensa en el portal de noticias La Gente. (21 de diciembre de 2007). Honduras: era colombiano el piloto muerto en avioneta. Disponible en http://www.radiolaprimerisima.com/noticias/resumen/23122/honduras-era-colombiano-el-piloto-muerto-en-avioneta/ 
La modalidad más común de intento de filtración por parte del narcotráfico es mediante la compra de información, la cual les permitía conocer la forma de operar de los medios ABD para poder evadir las acciones de control. Los narcotraficantes pueden pagar grandes cantidades de dinero a cambio de información sobre los despegues de aviones en misiones en contra de ellos como los OT47B, A-37B, OV-10, AT27, entre otros. También compran documentos, indicativos de llamada, programaciones, listados de frecuencias, etc. La Fuerza Aérea Colombiana, en este sentido, debió desarrollar los mecanismos necesarios para evitar que estos infiltrados, que en muchos casos eran muy difíciles de identificar, lograran tener acceso a la información.

Finalmente, transportar droga a bordo de aviones militares también fue objetivo para el narcotráfico. En 1996 fueron incautados tres kilos de heroína en una aeronave que transportaría al entonces presidente Ernesto Samper. Posteriormente, en 1998 por seguimiento de la misma FAC se incautaron en un C-130 Hércules de matrícula 1005 en Fort Lauderdale (La Florida, Estados Unidos) la nada despreciable cantidad de 600 kilos de cocaína y 13 libras de heroína, lo cual le costó el cargo al comandante de la FAC y al comandante del Comando Aéreo de Transporte Militar (CATAM) con sede en Bogotá.

La corrupción es un riesgo y una amenaza que ha afectado de diferentes formas a la FAC durante los últimos 30 ańos. Pero, ha sido menester de los diferentes comandantes crear los mecanismos para combatirla, estudios detallados de personal en cuanto a finanzas y origen familiar, pruebas de polígrafo obligatorias para comandantes y personal en cargos y tareas sensibles, procedimientos y protocolos de seguridad en todo lo relacionado a manejo de información, investigaciones profundas con vinculación penal y expulsión de personal con dudas fundamentadas en este sentido, son algunas de las medidas existentes en la lucha contra un enemigo invisible.

\section{Conclusiones}

Han sido, entonces, 30 años de lucha contra el narcotráfico desde la perspectiva de la Defensa Aérea y Antimisil de la Fuerza Aérea Colombiana; divididos en dos partes por el convenio Air Bridge Denial en 2003. Analizada toda la información disponible se puede evidenciar la efectividad de la estrategia de interdicción aérea planteada por la FAC en 2003, coincidente y como parte del lanzamiento del Convenio ABD firmado en el mismo ańo 
entre Colombia y los Estados Unidos. El ABD definitivamente cambió la forma en que la Fuerza Aérea combatía los vuelos ilegales, dando la oportunidad de liberar al país de este flagelo que no solo afectaban la seguridad aérea, sino que también permitían como parte integral del narcotráfico, la movilización de narcóticos, armas, dinero, personal y logística.

Si bien el proceso fue muy exitoso en lo meramente aéreo, es de anotar que dentro del marco del combate general del narcotráfico no impactó en gran medida el control de la oferta de drogas ilícitas, toda vez que los delincuentes migraron a otros países o a otros métodos de transporte que hicieron que la oferta de alcaloides se mantuviera. Cabe recordar que, las grandes ganancias provenientes del tráfico ilegal de drogas han incentivado a las mafias para que ante la lucha antinarcóticos busquen alternativas de choque con alto grado de adaptabilidad (ODM, s.f.). A esto hay que sumarle dos aspectos, por un lado, la política interna de Colombia especialmente durante la última década; en donde se flexibilizaron los controles a los cultivos ilícitos y a la producción de alcaloides, generando un crecimiento desbordado de la oferta, y, por otro lado, la falta de controles o permisividad por parte de los países hacia donde migró la problemática. Ahora bien, el problema mundial de las drogas requiere de un enfoque que incorpore dos perspectivas: I) el desarrollo de una estrategia desde la salud pública y la educación para desalentar, reducir y eliminar la demanda de estupefacientes (control de la demanda) y II) políticas orientadas al control efectivo de la oferta. Todo lo anterior, en pro de crear una estrategia integral que conduzca a resultados contundentes.

En temas de estrategia es claro que el modelo del ABD se aplicó conforme a la ecuación estratégica planteada por el TC (RA) Juan Ricardo Sánchez Hurtado en su libro "En la Mente de los Estrategas" (2012). El recuento histórico de los 17 años de aprendizajes del convenio, que se presenta en este capítulo, analizado a la luz de cada componente de la fórmula mencionada permite brevemente concluir lo siguiente:

1. Fines (F). Desde un comienzo la Fuerza Aérea Colombiana tenía claro cuál era el fin en materia de control del espacio aéreo en Colombia. Existía un problema grave de seguridad aérea y seguridad ciudadana que había que acometer. El fin último de toda la estrategia era el control del espacio aéreo impactando con esto aspectos tan importantes como la soberanía.

2. Medios (Me). Claramente se procuraron todos los elementos necesarios para combatir la amenaza existente, aviones, pilotos, operadores de equipos, infraestructura aeroportuaria, presupuesto y logística se evaluaron y procuraron, facilitando el inicio de la estrategia de manera efectiva. 
3. Modos (Mo). La forma es, tal vez, el componente que más impactó en el desarrollo de la estrategia, dado que hubo la necesidad de desarrollar buena parte de los procedimientos, convenios, reglas, normas que le dieran la posibilidad al ABD de ser exitoso.

4. Riesgos (R). Temas como la corrupción, la falta de recursos, los aspectos relacionados con los derechos humanos y legales, en general, formaron parte de la formulación de la estrategia. La mitigación de éstos permitió la efectividad estratégica.

5. Entorno del Adversario (EA). Existía una gran cantidad de información, producto de años de labores, que debió ser agrupada, clasificada, y analizada con detalle para enfocar los recursos en pro de atacar la amenaza hábilmente.

6. Entorno (En). Todos los demás aspectos que rodeaban la situación de la interdicción aérea fueron evaluados y, sumados a los demás componentes, conformaron una estrategia bien estructurada que ha funcionado eficazmente en Colombia.

Pero, el éxito de la estrategia no reside únicamente en tener un objetivo claro, contar con los medios necesarios para su implementación, los modos adecuados de acometerla, habiendo previsto todos los riesgos que afectaran el cumplimiento de ésta, conociendo completamente al enemigo y el ambiente propio; también es necesario controlar la estrategia, medirla. En este sentido la Fuerza Aérea Colombiana y el gobierno estadounidense hicieron una labor impecable, con certificaciones semestrales y anuales, controles mensuales, registros diarios, mediciones permanentes desde la óptica de la calidad, lo cual ayudó al cumplimiento de las metas trazadas.

Finalmente, la Defensa Aérea y Antimisil de la Fuerza Aérea Colombiana debe todo su desarrollo no solo al gran talento humano que la conforma, sino también a todo el proceso histórico que la FAC enfrentó. El narcotráfico es un problema complejo que aqueja a nuestro país y al planeta, que destruye vidas, economías, que genera violencia. Por ello, en Colombia las Fuerzas Militares evolucionaron, se equiparon, se entrenaron, se transformaron y adaptaron su estrategia para poder enfrentarlo. La FAC no fue ajena al proceso y gracias a una serie de circunstancias, al apoyo del gobierno norteamericano y a la construcción de un proceso basado en la experiencia y la historia aparece la Defensa Aérea que desarrollará e implementará en su momento la estrategia de interdicción aérea más exitosa de los últimos 30 años en Colombia. 


\section{Referencias}

Bèle, L. (21 de febrero de 2016). Lutte contre la drogue: les mensonges du Plan Colombie [en linea]. Le Figaro. Recuperado de http://blog.lefigaro.fr/amerique-latine/2016/02/lutte-contre-la-drogue-les-mensonges-du-plan-colombie.html

Benítez, J. (2014). Del modelo de interdicción aérea colombiana a la implementación de un sistema regional latinoamericano para la lucha contra el narcotráfico [tesis de especialización].

Bureau of International Narcotics and Law Enforcement Affairs [INL]. (2001). Peru Investigation Report: The April 20, 2001 Peruvian Shootdown Accident [en línea]. U.S. Department of State. Washington, DC. Recuperado de https://fas.org/irp/news/2001/08/peru_shootdown.html

Cajina, R. (2012). Centroamérica bajo asedio: Narcotráfico y debilidades institucionales [Boletín electrónico]. Instituto Español de Estudios Estratégicos - IEEE, (082). Madrid. Recuperado de http://www.ieee.es/Galerias/ fichero/docs_opinion/2012/DIEEEO82-2012_CentroamericaBajoAsedio_RCajina.pdf [Consultado el 26 de septiembre de 2017].

Comando de Operaciones Aéreas [COA]. (2020). Estrategia de Lucha Contra las Drogas. Fuerza Aérea Colombiana, Dirección Defensa Aérea y Anti-Misil. Reservado. Bogotá D.C.

Consejo Nacional de Estupefacientes. (2006). Resolución 0024 (julio 10): Por medio de la cual se dictan medidas tendientes al control de la aviación civil y se dictan otras disposiciones. Diario Oficial 46.349. Recuperado de http://www.suin-juriscol.gov.co/viewDocument.asp?.ruta=Resolucion/30034008

El Espectador. (17 de junio de 2009). Colombia y Perú realizarán ejercicios binacionales contra el narcoterrorismo [en línea]. Recuperado de https://www.elespectador.com/noticias/judicial/colombia-y-peru-realizaran-ejercicios-binacionales-contra-el-narcoterrorismo/

Ferrer, A. (1999). La globalización, la crisis financiera y América Latina. En Consejo Latinoamericano de Ciencias Sociales [CLACSO], Tiempos violentos. Neoliberalismo, globalización y desigualdad en América Latina (pp. 51-65). Buenos Aires: CLACSO. Recuperado de http://biblioteca.clacso. edu.ar/gsdl/collect/clacso/index/assoc/D1061.dir/5ferrer.pdf

Forero-Camacho, D. (2014). Vuelos Ilícitos, Un peligro para la aviación mundial en el Hemisferio Occidental [plegable]. Recuperado de https://www. infodefensa.com/wp-content/uploads/plegable_vuelos_ilicitos.pdf 
Fuerza Aérea Colombiana [FAC]. (2003). Comportamiento Aéreo Ilegal. Dirección de Defensa Aérea, Bogotá DC., Reservado.

Fuerza Aérea Colombiana. (2009). Fuerzas Aéreas de Colombia y Brasil inician ejercicios para combatir el narcotráfico en frontera [nota de prensa]. Recuperado de https://www.fac.mil.co/fuerzas-aéreas-de-colombia-y-brasil-inician-ejercicios-para-combatir-el-narcotráfico-en-frontera

Fuerza Aérea Colombiana. (2010). Ejercicios de interdicción aérea entre las Fuerzas Aéreas de Colombia y República Dominicana continúa con total éxito [nota de prensa]. Recuperado de https://www.fac.mil.co/en/ejercicios-de-interdicción-aérea-entre-las-fuerzas-aéreas-de-colombia-y-república-dominicana

Fuerza Aérea Colombiana. (2011a). Las Fuerzas Aéreas de Colombia y Honduras realizan el ejercicio de interdicción HOBCOL-1 [nota de prensa]. Recuperado de https://www.infodefensa.com/latam/2011/08/01/ noticia-las-fuerzas-aereas-de-colombia-y-honduras-realizan-el-ejercicio-de-interdiccion-honcol-1.html

Fuerza Aérea Colombiana. (2011b). Ejercicio de Interdicción Aérea HONCOLGUA I [nota de prensa]. Recuperado de https://www.fac.mil.co/ ejercicio-de-interdicción-aérea-honcolgua-i

Fuerza Aérea Colombiana [FAC]. (2014a). Lecciones Aprendidas en la Lucha contra el Narcotráfico. OEA/Ser.L/XIV.2.56. CICAD/doc.2154/14. Recuperado de http://www.cicad.oas.org/apps/Document.aspx?Id=3029

Fuerza Aérea Colombiana. (2014b). Colombia y Panamá realizan Ejercicio Combinado para la lucha contra el narcotráfico [nota de prensa]. Recuperado de https://www.fac.mil.co/colombia-y-panamá-realizan-ejercicio-combinado-para-la-lucha-contra-el-narcotráfico

Fuerza Aérea Colombiana. (2015). Ecuador: La FAE dio a conocer el entrenamiento Andes 1 contra el narcotráfico [nota de prensa]. Recuperado de https://www.fac.mil.co/ecuador-la-fae-dio-conocer-el-entrenamiento-andes-1-contra-el-narcotr\%C3\%A1fico

Global Security. (s.f.). OT-47B Citation II (Cessna 552). Recuperado de https://www.globalsecurity.org/military/systems/aircraft/ot-47b.htm

Gobierno del Perú, Ministerio de Transportes y Comunicaciones. (s.f.). Informe Final CIAA-ACCID-002-2001, correspondiente a la investigación de accidente, ocurrido a la aeronave modelo CESSNA A-185-E, matrícula OB-1408, de la compañía Asociación Bautista Evangelización Mundial, ocurrido el 20 de abril del 2001. Plataforma Digital Única del Estado 
Peruano. Recuperado de https://cdn.www.gob.pe/uploads/document/ file/425448/CIAA-ACCID-002-2001__OB1408_-_20APR01_.PDF

Grupo de Análisis de Narcotráfico, Área de Producción de Inteligencia, Dirección de Inteligencia Policial, Policía Nacional de Colombia \& Centro Integrado Estadístico Antinarcóticos, Área de Erradicación de Cultivos Ilícitos, Dirección de Antinarcóticos, Policía Nacional de Colombia. (junio de 2009). Comportamiento estratégico del narcotráfico, 1998-2008. Revista Criminalidad, 51(1), pp. 311-322. Disponible en http://www. scielo.org.co/pdf/crim/v51n1/v51n1a11.pdf

López-Muñoz, F., González, E., Serrano, M. D., Antequera, R., \& Álamo, C. (2011). Una visión histórica de las drogas de abuso desde la perspectiva criminológica (Parte I). Cuadernos de Medicina Forense, 17(1), pp. 21-33. Recuperado de http://scielo.isciii.es/scielo.php?pi$\mathrm{d}=\mathrm{S} 1135-76062011000100005 \&$ script $=$ sci_arttext\&tlng=en

Manual de Doctrina Básica Aérea y Espacial [MABDA]. (2013). Manual de Doctrina Básica. Fuerza Aérea Colombiana. Bogotá D.C. Recuperado de https://www.fac.mil.co/sites/default/files/fac_o-e_madba_cuarta_edicion.pdf

Mejía, D., \& Gaviria, A. (2011). Politicas Antidroga en Colombia: éxitos, fracasos y extravios. Bogotá: Ediciones Uniandes, Bogotá, DC. Recuperado de http://focoeconomico.org/2011/04/19/politicas-antidroga-en-colombia-exitos-fracasos-y-extravios/

National Commission on Terrorist Attacks upon the United States. (2004). The 9/11 Commission report: final report of the National Commission on Terrorist Attacks upon the United States. Authorized ed., 1st ed. New York: Norton.

Neira, J. (s.f.) Fuerza Aérea Colombiana líder en ABD [nota de prensa]. Portal Fuerza Aérea Colombiana. Recuperado de https://www.fac.mil.co/ fuerza-aérea-colombiana-1\%C3\%ADder-en-abd

Nye, J. (2009). Get Smart: Combining Hard and Soft Power. Foreign Affairs, 88(4), pp. 160-163. Recuperado de www.jstor.org/stable/20699631

Observatorio de Drogas de Colombia [ODC]. (2005). Colombia. Censo de cultivos ilícitos. Naciones Unidas, Oficina contra la droga y el delito. Recuperado de http://www.odc.gov.co/Portals/1/publicaciones/pdf/oferta/ censos/OF02012004-censo-cultivos-coca-2004-.pdf 
Observatorio de Drogas de Colombia [ODC]. (s.f.). Mercado y Precios. Recuperado de http:/www.odc.gov.co/problematica-drogas/oferta-drogas/ mercado

Oficina de Naciones Unidas contra la Droga y el Delito [UNODC]. (2003). Global Illicit Drug Trends. Naciones Unidas: New York. Recuperado de https://www.unodc.org/pdf/trends2003_www_E.pdf

Oficina de Naciones Unidas contra la Droga y el Delito [UNODC]. (2012). Cocaína desde Suramerica a los Estados Unidos. Delincuencia organizada transnacional en Centroamérica y el Caribe. Recuperado de https://www. unodc.org/documents/toc/Reports/TOCTASouthAmerica/Spanish/ TOCTA_CA_Caribb_cocaina_SA_US_ES.pdf

Oficina de Naciones Unidas contra la Droga y el Delito [UNODC]. (2019). Informe Mundial sobre las Drogas. Observatorio de Drogas de Colombia. Recuperado de http://www.odc.gov.co/Portals/1/publicaciones/pdf/internacionales/WDR2019_B1_S.pdf

Organización de las Naciones Unidas [ONU]. (2003). COLOMBIA - Coca Survey for December 2002 \& Semi-Annual Estimate for July 2003. Oficina contra las Drogas y el Crimen [UNODC]. New York. http://www. unodc.org/pdf/publications/colombia_report_2003-09-25.pdf

Organización de las Naciones Unidas [ONU]. (2017). Colombia, Monitoreo de territorios afectados por cultivos ilícitos 2016. Oficina de las Naciones Unidas contra la Droga y el Delito [UNODC]. Bogotá D.C. Disponible en https://www.unodc.org/documents/colombia/2017/julio/CENSO_2017_WEB_baja.pdf

Organización de las Naciones Unidas [ONU]. (2016). World Drug Report. Oficina de las Naciones Unidas contra la Droga y el Delito [UNODC]. Recuperado de http://www.unodc.org/doc/wdr2016/WORLD_DRUG_ REPORT_2016_web.pdf

Organización de los Estados Americanos [OEA]. (2003). Declaración sobre Seguridad en las Américas. Conferencia Especial sobre Seguridad [CES], (1 de diciembre/ 03 rev. 1). Recuperado de http://www.oas.org/36AG/ espanol/doc_referencia/DeclaracionMexico_Seguridad.pdf

Organización de los Estados Americanos [OEA]. (2013). El Problema de las Drogas en las Américas: Estudios (2013). La Economía del Narcotráfico. Organización de Estados Americanos. Recuperado de http://www.cicad. oas.org/drogas/elinforme/informeDrogas2013/laEconomicaNarcotrafico_ESP.pdf 
Pelcastre, J. (16 de diciembre de 2016). Colombia y México fortalecen interdicción aérea contra tráfico de drogas [en línea]. Revista Militar DIÁ$L O G O$. Recuperado de https://dialogo-americas.com/es/articles/colombia-and-mexico-enhance-air-interdiction-of-drug-trafficking/

Presidencia de Colombia. (2003). Política de Defensa y Seguridad Democrática. Recuperado de https://www.oas.org/csh/spanish/documentos/ Colombia.pdf

Real Academia Española [RAE]. (2017). Estrategia. En Diccionario de la lengua española. Recuperado de http://dle.rae.es/?id=GxPofZ8

Robertson, G. (2002). Able to forvige, not forget, Peru Air Attack. Washington Post. Recuperado de https://www.washingtonpost.com/archive/ local/2002/07/06/able-to-forgive-not-forget-peru-air-attack/0bed6a2f16b0-4a21-97d4-8cb600b1fe1d/

Rodríguez, F., Itzhak, M., \& Larrea, L. (2013). Interdicción aérea en Brasil y Colombia y su incidencia en el tráfico aéreo ilícito asociado al narcotráfico 2001-2011: Consideraciones para Ecuador. Instituto de Altos Estudios Nacionales. Quito. Recuperado de http://repositorio.iaen.edu.ec/ handle/24000/3684

Roncken, T. (1999). Air Bridge Denial: El éxito de un fracaso. Transnational Institute - TNI. Amsterdam. Recuperado de https://www.tni.org/my/node/12074? content_language=es

Sánchez-Hurtado, J. (2012). En la Mente de los Estrategas. Bogotá D.C.: Escuela Superior de Guerra.

Unidad Administrativa Especial de Aeronáutica Civil. [Aerocivil]. (2013). Interceptación de Aeronaves Civiles. Publicación de tipo público dirigida a los pilotos y personal aeronáutico. Aeronautical Information Publication [AIP]. Colombia. Recuperado de http://www.aerocivil.gov.co/ servicios-a-la-navegacion/servicio-de-informacion-aeronautica-ais/Documents/13\%20ENR\%201.12.pdf

United States Government Accountability Office [GAO]. (2005). Drug Control, Air Bridge Denial Program in Colombia has implemented new safeguards, but its effect on drug trafficking is not clear. Report to Congressional Requesters. Recuperado de https://www.gao.gov/assets/250/247612. pdf

Usme, M. (2013). Grupo Regional de Interdicción Aérea: Una Contribución del Modelo Colombiano al Control del Tráfico Aéreo Ilegal en Centroamérica [tesis de maestría]. Universidad Externado de Colombia, Bogotá D.C. 
Valencia, A. (1999). Las seis etapas del narcotráfico. En El Tiempo. Bogotá D.C. Recuperado de http://www.eltiempo.com/archivo/documento/ MAM-948277

Veillete, C. (2005). Plan Colombia: A Progress Report. Analyst in Latin American Affairs, Foreign Affairs, Defense, and Trade Division. Recuperado de https://fas.org/sgp/crs/row/RL32774.pdf

Zerpa, F. (25 de abril 2017). El Origen de "Divide y Reinarás”. Culturizando. com. Recuperado de https://culturizando.com/origen-divide-reinaras/

Zuñiga, C. (2011). JIATF-S, Ejemplo de trabajo conjunto dedicado a la interdicción de droga. Revista de Marina de Chile. Viña del Mar. Recuperado de http://revistamarina.cl/revistas/2011/3/cruzat.pdf 